\title{
CARACTERÍSTICAS QUALITATIVAS DO MÚSCULO Longissimus dorsi DE ANIMAIS Bos indicus TRATADOS COM VITAMINA $D_{3}$
}

\author{
Aparecida Carla de Moura Silveira Pedreira
}

\author{
Tese apresentada à Escola Superior de Agricultura \\ "Luiz de Queiroz", Universidade de São Paulo, para \\ obtenção do título de Doutor em Agronomia, Área de \\ Concentração: Ciência Animal e Pastagens.
}

P I R A C I C A B A

Estado de São Paulo - Brasil

Maio - 2002 


\title{
CARACTERÍSTICAS QUALITATIVAS DO MÚSCULO Longissimus dorsi DE ANIMAIS Bos indicus TRATADOS COM VITAMINA $D_{3}$
}

\author{
aparecida Carla de Moura Silveira Pedreira \\ Zootecnista
}

Orientador: Prof. Dr. SILA CARNEIRO DA SILVA Co-Orientador: Prof. Dr. ALBINO LUCHIARI FILHO

\begin{abstract}
Dissertação apresentada à Escola Superior de Agricultura "Luiz de Queiroz", Universidade de São

Paulo, para obtenção do título de Doutor em Agronomia, Área de Concentração: Ciência Animal e Pastagens.
\end{abstract}

P I R A C I C A B A

Estado de São Paulo - Brasil

Maio - 2002 


\section{Dados Internacionais de Catalogação na Publicação (CIP)} DIVISÃo DE BIBLIOTECA E DOCUMENTAÇÃO - ESALQ/USP

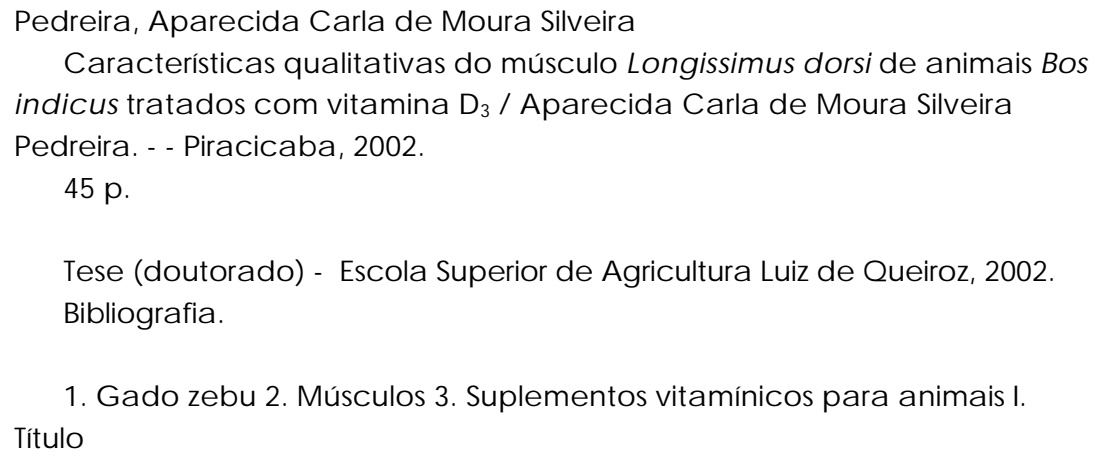

CDD 636.291

\section{"Permitida a cópia total ou parcial deste documento, desde que citada a fonte - $O$ autor"}


Aos meus queridos João Guilherme e Carlos Guilherme Silveira Pedreira,

\section{Dedico}

À minha adorada sogra Sônia Esther Silveira Pedreira

(in memoriam)

\section{Ofereço}




\section{AGRADECIMENTOS}

Ao Prof. Dr. Albino Luchiari Filho, pela orientação, amizade e confiança, que muito contribuíram para o meu enriquecimento profissional e para a realização deste trabalho;

Ao Prof. Dr. Sila Carneiro da Silva, pelo apoio e colaboração na realização deste trabalho;

Aos Professores do Departamento de Produção Animal da Escola Superior de Agricultura "Luiz de Queiroz", pelos ensinamentos no decorrer do curso;

Às funcionárias do Departamento de Produção Animal da ESALQ/USP, Claudia, Vera e Creide, pela simpatia, colaboração e amizade;

Aos colegas do curso de Pós-graduação em Ciência Animal e Pastagens, pela amizade e companheirismo;

Aos Prof. Dr. Pedro Eduardo Felício (FEA/UNICAMP), Prof. Dr. Paulo Roberto Leme (FZEA/USP), Prof ${ }^{\mathrm{a}}$. Dr ${ }^{\mathrm{a}}$. Ivanete Susin (ESALQ/USP) e Prof. Dr. Claudio Maluf Haddad (ESALQ/USP), pela participação na Banca Examinadora;

À ROCHE, na pessoa do Dr. Antônio Rubens Chagas Lima, pela doação do produto ROVIMIX D;

Ao Pesquisador do Instituto de Zootecnia de Brotas, Vanderley Benedito de Oliveira Leite, pela amizade e apoio na realização deste trabalho;

Ao Pesquisador do Instituto de Zootecnia de Nova Odessa, Dr. Guilherme Alleoni, pelo auxílio na utilização do aparelho Warner Braztler Shear Force Device;

À Prof ${ }^{-}$. Dra. Marta Helena Fillet Spoto e a funcionária Juliana Antunes Galvão do Departamento de Agroindústrias, Alimentos e Nutrição, do Setor de 
Processamento de Alimentos, pela grande amizade e ajuda nas análises sensoriais;

À Prof ${ }^{\mathrm{a}}$. Dr ${ }^{\mathrm{a}}$. Marília Oetterer e a funcionária Ivani Aparecida Marchetto Moreno do Departamento de Agroindústrias, Alimentos e Nutrição, do Setor de Processamento de Alimentos pela amizade e auxílio na utilização da embaladora à vácuo;

Ao Prof. Dr. César Gonçalves de Lima, do Departamento de Ciências Básicas da FZEA/USP e a Prof. Dr ${ }^{\mathrm{a}}$. Maria Cristina Stolf Nogueira, do Departamento de Ciências Exatas da ESALQ/USP pelos ensinamentos e grande auxílio nas análises estatísticas deste trabalho;

À bibiotecária Eliana Maria Garcia Sabino pela correção das referências bibliográficas e fornecimento da ficha catalográfica;

À Fernanda Nonatto Rizzaro e sua mãe Dra. Sylvia Nonatto pelo grande ajuda e apoio;

À Família Guerrini que nos adotaram como filhos, irmãos e netos e que estiveram presentes nos momentos mais difíceis dessa fase da vida;

À FAPESP, pela Bolsa de Doutorado;

Aos meus pais e irmãos, pelo incentivo, estímulo e amor;

À Deus, por tudo. 


\section{SUMÁRIO}

LISTA DE TABELAS............................................................................... viii

LISTA DE QUADROS.........................................................................

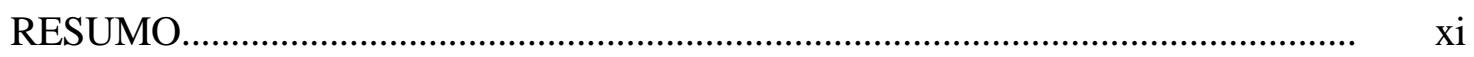

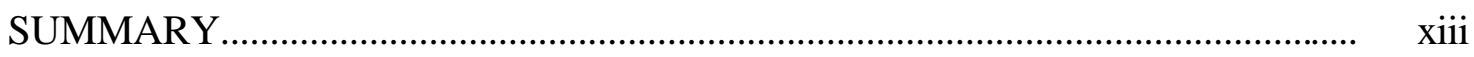

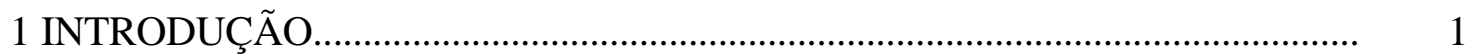

2 REVISÃO DE LITERATURA..................................................................... 4

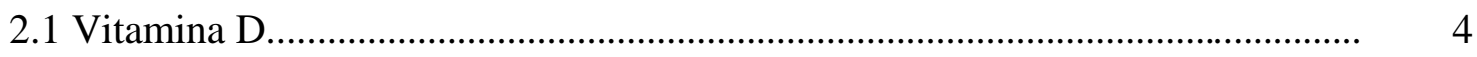

2.2 Tipos de Cálcio Existentes no Plasma...................................................................... 7

2.3 O Papel do Cálcio na Carne ........................................................................... 8

2.4 Vitamina D: Requerimentos, Recomendações e Maciez da Carne.................... 8

2.5 Resíduos de Vitamina $\mathrm{D}_{3}$ e Saúde Humana.................................................... 16

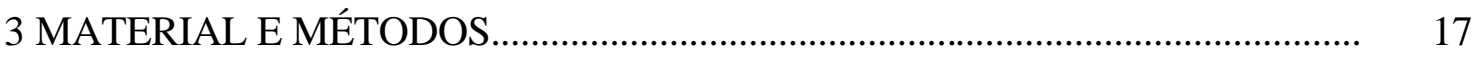

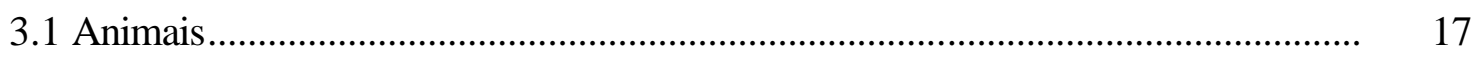

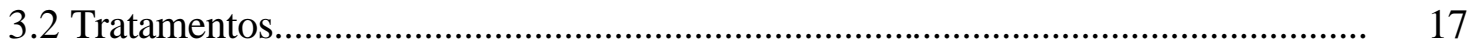

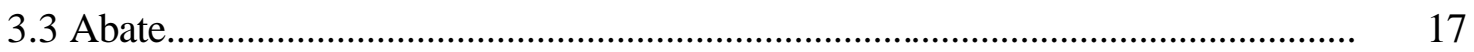

3.4 Força de Cisalhamento e Perdas por Cozimento............................................... 18

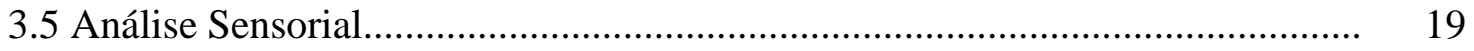

3.6 Análise de Minerais para Sangue e Carne........................................................ 20

3.7 Análise Estatística..................................................................................... 20

4 RESULTADOS E DISCUSSÃO ...................................................................... 21

4.1 Características da Carcaça................................................................................ 21

4.2 Teor de Glicose no Plasma................................................................................ 25 
4.3 Concentração de Minerais no Plasma................................................................. 25

4.4 Concentração de Minerais no Músculo.............................................................. 27

4.5 Perdas por Evaporação (PE) ........................................................................ 29

4.6 Perdas por Gotejamento (PG) …................................................................... 30

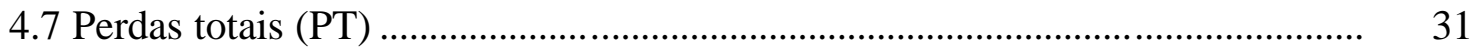

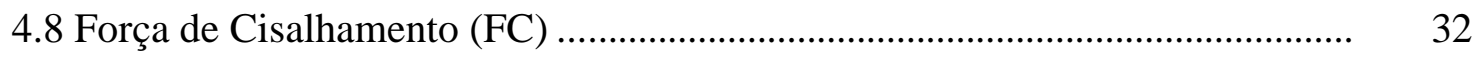

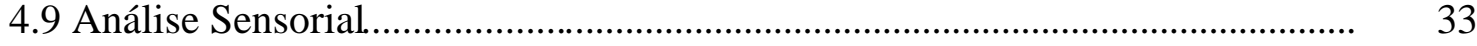

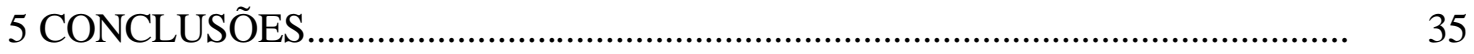

REFERÊNCIAS BIBLIOGRÁFICAS............................................................... 37 


\section{LISTA DE TABELAS}

Página

1 Valores médios das características de carcaças de animais Bos indicus suplementados com vitamina $\mathrm{D}_{3}$ por 9 dias consecutivos antes do abate.................................... 22

2 Média dos quadrados mínimos (LSM) e erro padrão (EP) das características de carcaça com significância de 5\% para animais Bos indicus suplementados com $\begin{array}{lllllllllll}\text { vitamina } & \mathrm{D}_{3} & (\text { dose } & \mathrm{X} & 10^{6} & \mathrm{UI} / \mathrm{an} / \mathrm{dia}) & \text { por } & 9 & \text { dias } & \text { consecutivos antes do }\end{array}$

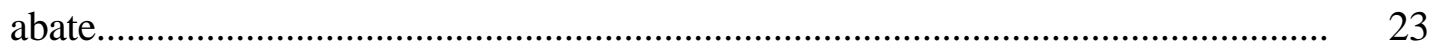

3 Contrastes lineares para as características de carcaça de animais Bos indicus suplementados com vitamina $\mathrm{D}_{3}$ por 9 dias consecutivos antes do abate............. 24

4 Média dos quadrados mínimos (LSM) e erro padrão (EP) do teor de glicose para animais Bos indicus suplementados com vitamina $\mathrm{D}_{3}$ por 9 dias consecutivos antes do abate.

5 Média dos mínimos quadrados, média geral, coeficiente de correlação e significância das concentrações de minerais no plasma de animais Bos indicus suplementados com vitamina $\mathrm{D}_{3}$ por 9 dias consecutivos antes do abate. 26 
6 Média dos mínimos quadrados, média geral, coeficiente de correlação e significância das concentrações de minerais no plasma de animais Bos indicus suplementados com vitamina $D_{3}$ por 9 dias consecutivos antes do abate.

7 Médias dos quadrados mínimos das perdas por evaporação (\%) e efeito "sliced" em relação ao tratamento, tempo de maturação e a interação tratamento $X$ tempo de maturação em carcaças de animais Bos indicus suplementados com vitamina $\mathrm{D}_{3}$ por 9 dias consecutivos antes do abate.

8 Médias dos quadrados mínimos de perdas por gotejamento (\%) e efeito "sliced" em relação ao tratamento, tempo de maturação e a interação tratamento $\mathrm{X}$ tempo de maturação em carcaças de animais Bos indicus..................................................... $\quad 30$

9 Médias dos quadrados mínimos de perdas totais (\%) e efeito "sliced" em relação ao tratamento, tempo de maturação e a interação tratamento $X$ tempo de maturação em carcaças de animais Bos indicus suplementados com vitamina $\mathrm{D}_{3}$ por 9 dias consecutivos antes do abate.

10 Médias dos quadrados mínimos de forca de cisalhamento $(\mathrm{Kg})$ e efeito "sliced" em relação ao tratamento, tempo de maturação e a interação tratamento $\mathrm{X}$ tempo de maturação em carcaças de animais Bos indicus suplementados com vitamina $\mathrm{D}_{3}$ por 9 dias consecutivos antes do abate

11 Valores médios das características de sabor, suculência, maciez e análise geral da análise sensorial realizada em carcaças de animais Bos indicus suplementados com $\begin{array}{lllllll}\text { vitamina } & \mathrm{D}_{3} & \text { por } & 9 & \text { dias } & \text { consecutivos antes do }\end{array}$ abate 


\section{LISTA DE QUADROS}

Página

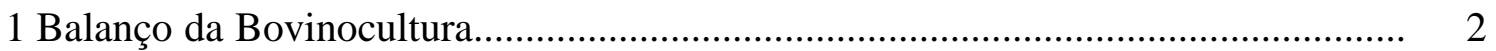




\title{
CARACTERÍSTICAS QUALITATIVAS DO MÚSCULO Longissimus dorsi DE ANIMAIS Bos indicus TRATADOS COM VITAMINA D
}

\author{
Autora: A. CARLA M.S. PEDREIRA \\ Orientador: Prof. Dr.SILA CARNEIRO DA SILVA \\ Co-Orientador: Prof. Dr.ALBINO LUCHIARI FILHO
}

\section{RESUMO}

Muitas são as técnicas empregadas para se amaciar a carne. Entre as mais recentes está o uso de vitamina $\mathrm{D}_{3}$, que tem importância na mobilização do cálcio, e é importante na ativação das proteases cálcio-dependentes ( $\mu$ - e m-calpaína). Neste estudo, 36 machos inteiros (Nelore) foram suplementados por via oral com 4 níveis de vitamina $\left(0,3\right.$, 6 e 9 milhões de UI de vitamina $\mathrm{D}_{3} /$ animal/dia) por um período de dez dias antes do abate. Após esse período de suplementação, os animais foram abatidos e o amaciamento e perdas por cozimento (aos dias 1, 8 e 15 dias de maturação), análise sensorial, pH, área do olho do lombo, espessura de gordura, rendimentos da carcaça, concentração de minerais no plasma (cálcio, magnésio, fósforo, sódio e potássio) e de cálcio no músculo Longissimus dorsi foram estudados. Os resultados mostraram que, 
não houveram diferenças significativas $(\mathrm{P}>0,05)$ para as principais características da carcaça, glicose plasmática, concentração de minerais no plasma e músculo, perdas por evaporação, e suculência estimada pela análise sensorial. Houve efeito das doses de vitamina $\mathrm{D}_{3}$ e tempo de maturação $(\mathrm{P}<0,05)$, sobre as perdas por gotejamento, perdas totais por cozimento, força de cisalhamento e maciez, sabor e avaliação sensorial. Para as perdas por gotejamento e perdas totais, as menores perdas foram aquelas para a dose $6 \times 10^{6} \mathrm{UI} / \mathrm{an} /$ dia. Para a força de cisalhamento (FC)a dose $0 \times 10^{6} \mathrm{UI} / \mathrm{an} /$ dia resultou na menor FC encontrada e em relação ao tempo de maturação foi encontrada uma tendência de redução, onde quanto maior o tempo de maturação, menor a força de cisalhamento encontrada. Para as características estudadas na análise sensorial, a dose $3 \times 10^{6} \mathrm{UI} / \mathrm{an} / \mathrm{dia}$ afetou positivamente as características de maciez, sabor e avaliação geral. 


\title{
Longissimus dorsi MUSCLE QUALITY CHARACTERISTICS FROM Bos indicus ANIMALS VITAMIN D $_{3}$ TREATED
}

\author{
Author: A. CARLA M.S. PEDREIRA \\ Adviser: Prof. Dr.SILA CARNEIRO DA SILVA \\ Co-Adviser: Prof. Dr.ALBINO LUCHIARI FILHO
}

SUMMARY

Among several techniques to improve beef tenderness, vitamin $\mathrm{D}_{3}$ (important to calcium mobilization) become, recently, to be used to actives the intracellular calciumdependent proteases ( $\mu$ - and m-calpain). Ten days prior to slaughter 36 intact males were fed with $0,3,6$ and 9 million IU of supplemental vitamin $D_{3}$ per head per day. After that period, the animals were slaughtered and tenderness (shear force), cooking losses $(1,8$ and 15 days of aging time), sensory evaluation, muscle $\mathrm{pH}$, Longissimus muscle area, fat thickness, carcass yield grade, blood plasma measurements (glucose, calcium, magnesium, sodium and potassium), and muscle mineral levels from the Longissimus dorsi muscle were determined. The results showed that, there were not significant 
differences $(\mathrm{P}>0,05)$ for carcass quantitative and qualitative traits, blood plasma glucose concentration, blood plasma and muscle minerals concentration, evaporation losses, and sensory juiceness. There was effect of vitamin $D_{3}$ doses and ageing $(P<0,05)$ on drip loss and total cooking loss, shear force, sensory tenderness, flavor and overall palatability. For drip and total loss, the smallest losses went those to 6x106 UI/an/day. 0x106 UI/an/day dose resulted in the smallest shear force and in ageing time was observed a reduction tendency, where the longer the ageing time, smaller was the shear force observed. For sensory evaluation, $3 \times 10^{6} \mathrm{UI} / \mathrm{an} /$ day dose affected the tenderness, flavor and overall palatability characteristics positively. 


\section{INTRODUÇÃO}

O Brasil possui o maior rebanho comercial do mundo, ficando atrás apenas da Índia.

Nos últimos 5 anos a pecuária brasileira sofreu intensas mudanças, como pode ser

observado no Quadro 1. Entre essas mudanças podemos citar um crescimento no número de animais do rebanho e na quantidade de animais abatidos; uma maior produção de carne, na taxa de abate, nas exportações e redução das importações, explicadas pelo uso de novas tecnologias de produção, associadas a demanda dos mercados interno e externo. Crescimento que também foi observado na população brasileira e no consumo interno.

No Brasil, a carne produzida é predominantemente de animais Bos indicus sendo considerada menos macia por apresentar maior atividade da calpastatina (Whipple et al., 1990).

A maciez da carne é influenciada por fatores ante e post mortem. Entre os fatores ante mortem podemos citar o estresse, genética, alimentação e a idade ou maturidade. Dentre os fatores post mortem podemos citar o declínio de $\mathrm{pH}$, o tipo de resfriamento (o qual não sendo adequado pode causar problemas como encurtamento pelo frio, rigor de descongelamento, rigor de aquecimento e processamento acelerado), o uso de estimulação elétrica, maturação e métodos de cocção. Estes fatores serão responsáveis pelos efeitos sobre a capacidade de retenção de água (CRA), cor, firmeza, maciez, sabor, suculência, capacidade de emulsificação, rendimentos do processo e cor dos produtos processados. 


\begin{tabular}{lccccc}
\hline \multicolumn{1}{c}{ BRASIL } & 2001 & 2000 & 1999 & 1998 & 1997 \\
\hline Rebanho * & 161,8 & 159,4 & 157,4 & 154,7 & 153,6 \\
Abate * & 34,1 & 32,8 & 31,0 & 31,4 & 31,5 \\
Produção *** & 7.022 & 6.681 & 6.422 & 6.413 & 6.409 \\
Taxa de abate (\%) & 21,1 & 20,6 & 19,7 & 20,3 & 20,5 \\
Exportação *** & 710 & 554 & 541 & 370 & 287 \\
Importação *** & 36 & 57 & 42 & 79 & 112 \\
População Brasileira ** & 172,4 & 169,4 & 166,4 & 163,1 & 159,9 \\
Consumo interno *** & 6.348 & 6.184 & 5.923 & 6.122 & 6.233 \\
\hline
\end{tabular}

Fonte: ANUALPEC 2001

Quadro 1- Balanço da Bovinocultura

Rebanho em 31 de dezembro de cada ano

* Milhares de Cabeças

** Milhões de Habitantes

*** Milhares de Toneladas de Equivalente Carcaça

Uma vez que a maciez da carne é a característica organoléptica mais importante para o consumidor; ser influenciada por fatores ante e post mortem e os animais criados no Brasil apresentam carne menos macia, uma das soluções seria a utilização de métodos tecnológicos para melhorar sua maciez.

Nos últimos anos muitas técnicas foram empregadas para amaciar a carne como: resfriamento retardado, manejo de câmara fria, suspensão pélvica, estimulação elétrica, maturação, utilização de cloreto de cálcio e propionato de cálcio. Estas técnicas foram estudadas e empregadas de forma individual ou em combinação, e todos esses métodos se baseiam, principalmente, em aumentar a maciez através do aumento do comprimento do sarcômero, aumento da atividade autolítica das enzimas, aumento da liberação de enzimas lisossômicas, aumento da tensão sobre diversos músculos do lombo e da perna, minimizar a desnaturação protéica, perda da força de tensão do componente miofibrilar da célula muscular 
devido a desintegração das bandas Z, ruptura da fibra muscular e fornecimento de cálcio exógeno para as proteases dependentes de cálcio ( $\mu$ - e m-calpaínas). Este processo consiste em acelerar o amaciamento através da ativação de m-calpaína, que em condições normais pós-morte é pouco ativada, por necessitar de uma maior concentração de íons cálcio para ser ativada.

A vitamina $D_{3}$ é utilizada rotineiramente na dieta para prevenir problemas de febre do leite em vacas em lactação, através de sua atuação no metabolismo de cálcio elevando o nível sanguiíneo do mesmo (Morgan, 1998a,b). Seu uso no amaciamento da carne é uma tecnologia recente, e consiste no fornecimento de médios a altos níveis da vitamina $\mathrm{D}_{3}$ por via oral, o que disponibilizaria cálcio o suficiente para ativar as proteases dependentes de cálcio ( $\mu$ - e m-calpaínas) e acelerar o processo de amaciamento da carne (Montgomery et al., 2000a,b,c; Morgan, 2000; Swanek et al., 1999a,b,c).

O presente estudo teve como objetivos estudar o amaciamento e perdas por cozimento (aos dias 1, 8 e 15 dias de maturação), análise sensorial, pH da carne, área do olho do lombo, espessura de gordura, rendimentos da carcaça, concentração de cálcio, magnésio, fósforo, sódio e potássio plasmático e de cálcio no músculo Longissimus dorsi, em animais Bos indicus (Nelore), recebendo 4 níveis de vitamina $\mathrm{D}_{3}(0,3,6$ e 9 milhões de UI/animal/dia) por um período de 10 dias antes do abate. 


\section{REVISÃO DE LITERATURA}

\subsection{Vitamina D}

As vitaminas são um grupo complexo de compostos orgânicos requeridos em pequenas quantidades pelo organismo para a manutenção dos sistemas vitais. Apesar de serem consideradas essenciais na dieta (necessárias para que ocorram reações metabólicas específicas no interior das células), as vitaminas são obtidas através dos alimentos (em pequenas quantidades).

As vitaminas são classificadas segundo a solubilidade, sendo agrupadas em hidrosolúveis (solúveis em água) e em liposolúveis (solúveis em gorduras). No grupo das hidrosolúveis são encontradas as vitaminas do complexo B e C. No grupo das liposolúveis estão as vitaminas A, D, E e K (Andriguetto et al., 1981; Gaman \& Sherrington, 1981).

No organismo, a vitamina D é necessária para a absorção de cálcio e fósforo, normal mineralização dos ossos, mobilização do cálcio do osso e imunidade. A função principal da vitamina é elevar os níveis de cálcio e fósforo do plasma por supersaturação, no qual é necessária para a mineralização normal dos ossos. Isto se realiza estimulando a absorção intestinal do cálcio e fósforo, a mobilização dos ossos já formados e melhorando a reabsorção renal (Blezinger, 2001; Bondi, 1988; Gaman \& Sherrington, 1981; Weiss, 1998).

A vitamina $\mathrm{D}$ é encontrada em 2 formas na natureza, a vitamina $\mathrm{D}_{2}$ (ergocalciferol) e a vitamina $\mathrm{D}_{3}$ (colecalciferol). A vitamina $\mathrm{D}_{2}$ é conhecida como sendo a forma sintética da vitamina, mas apresentando a mesma atividade que vitamina natural $\left(\mathrm{D}_{3}\right)$. Ela é sintetizada por radiação ultravioleta a partir do esteróide ergosterol (presente nos vegetais, fungos e levedura). Esta é a forma como a vitamina é adicionada aos alimentos industrializados, como a margarina e alimentos infantis. A vitamina $D_{3}$ é conhecida como a forma natural (presente nos tecidos animais), podendo ser formada sob a pele pela influência dos raios solares (radiação ultravioleta) sobre o 7-dehidrocolesterol (Blezinger, 2001; Bondi, 1988; Gaman \& Sherrington, 1981). 


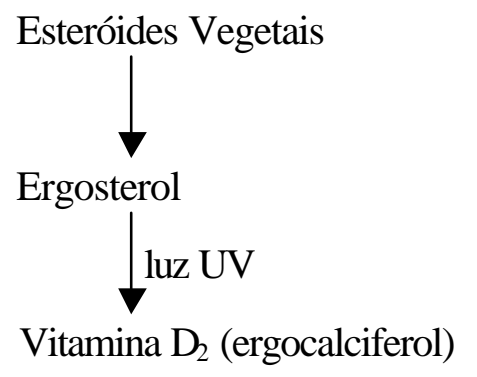

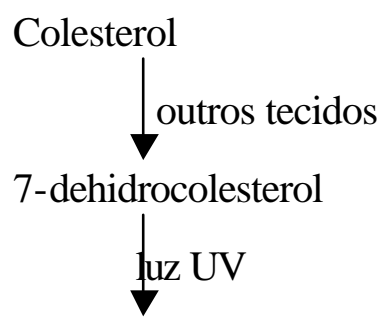

Vitamina $\mathrm{D}_{3}$ (colecalciferol)

Segundo Bondi (1998) e Roche (2000), sua presença na ração animal não é necessária, pois a exposição dos animais a luz solar faz com que os fótons de alta energia UV (290-315 nm) penetrem na epiderme e transformem o 7-dehidrocolesterol (pró-vitamina $\mathrm{D}_{3}$ ) a pré-vitamina $D_{3}$. Uma vez formada, a pré-vitamina $D_{3}$ transforma-se em vitamina $D_{3}$ por isomerização térmicamente induzida, levando de 2-3 dias para que isso ocorra.

Para os mamíferos a vitamina $\mathrm{D}_{2}$ apresenta menor atividade biológica que a vitamina $\mathrm{D}_{3}$, devido seus metabólitos apresentarem menor afinidade pelas proteínas transportadoras presentes no plasma (Bondi, 1988).

A absorção de vitamina D se realiza como os outros lipídeos, no trato intestinal. A vitamina D absorvida no intestino chega ao sangue e é transferida para a maioria dos tecidos do organismo, em especial o fígado. A vitamina $\mathrm{D}_{3}$ (exógena e endógena) se metaboliza no fígado para formar 25-hidroxi-vitamina $\mathrm{D}_{3}\left[25(\mathrm{OH}) \mathrm{D}_{3}\right]$. A $\left[25(\mathrm{OH}) \mathrm{D}_{3}\right]$ não atua diretamente nos tecidos de destino, sendo que deve ser modificada novamente; sendo então transportada até o rim onde é hidrolizada a 1,25-dehidroxi-vitamina $\mathrm{D}_{3}\left[1,25(\mathrm{OH})_{2} \mathrm{D}_{3}\right]$. Esta forma é a forma fisiologicamente ativa da vitamina $\mathrm{D}$, apresentando cinco vezes mais atividade do que a 25-hidroxi-vitamina $\mathrm{D}_{3}$ (Bondi, 1988; NRC, 1996).

Vitamina $\mathrm{D}_{3} \stackrel{\text { FíGADO }}{\longrightarrow}$ 25-hidroxi-colecalciferol $25(\mathrm{OH}) \mathrm{D}_{3}$
RIM 25-hidroxi-colecalciferol $1,25(\mathrm{OH})_{2} \mathrm{D}_{3}$ 
A $1,25(\mathrm{OH})_{2} \mathrm{D}_{3}$ é considerada a forma hormonal da vitamina $\mathrm{D}$, uma vez que cumpre os critérios empregados para os hormônios, ou seja, é produzida em um local (no rim) e irá atuar em outro lugar (intestino, ossos e dentes, como tecidos de destino); sendo a sua produção regulada por um mecanismo de retroalimentação (Bondi, 1988; Gaman \& Sherrington, 1981).

A formação de $25(\mathrm{OH}) \mathrm{D}_{3}$ é controlada no fígado, evitando-se assim uma possível formação excessiva de vitamina D. Assim, a conversão controlada de vitamina D permite conservar a vitamina $\mathrm{D}$ para sua utilização posterior, já que a vitamina $\mathrm{D}$, mas não seus derivados, pode conservar-se em todos os tecidos ricos em lipídeos do organismo (Bondi, 1988).

A forma arrculante no plasma $\left[25(\mathrm{OH}) \mathrm{D}_{3}\right]$ não é regulada pelos níveis de cálcio e fósforo do soro sangüíneo, entretanto, o ritmo da formação do metabólito $1,25(\mathrm{OH})_{2} \mathrm{D}_{3}$ está relacionado com as concentrações de cálcio e fósforo do soro. Para aumentar a calcemia é necessária maiores quantidades de $1,25(\mathrm{OH})_{2} \mathrm{D}_{3}$. Altos níveis de cálcio reduzem a formação de $1,25(\mathrm{OH})_{2} \mathrm{D}_{3}$ e os baixos níveis a estimulam. Ainda, a falta de cálcio determina a secreção do hormônio da paratireóide que por sua vez, estimula a conversão enzimática de $25(\mathrm{OH}) \mathrm{D}_{3}$ em $1,25(\mathrm{OH})_{2} \mathrm{D}_{3}$. Por outro lado, o hormônio da paratireóide estimula diretamente a absorção do cálcio para a formação dos ossos. Uma ação regulatória mais importante ocorre no fígado, através da indução da 24-hidroxilação, a qual leva a formação de $24,25(\mathrm{OH})_{2} \mathrm{D}_{3}$ do $25(\mathrm{OH}) \mathrm{D}_{3}$ e de $1,24,25(\mathrm{OH})_{2} \mathrm{D}_{3}$ do $1,25(\mathrm{OH})_{2} \mathrm{D}_{3}$. A 24-hidroxilação leva a inativação de potentes metabólitos da vitamina D (Bondi, 1988).

O principal local de atividade da $1,25(\mathrm{OH})_{2} \mathrm{D}_{3}$ é o intestino, onde aumenta a absorção de cálcio. Ainda, sugere-se que o 24,25 $(\mathrm{OH})_{2} \mathrm{D}_{3}$ seja o responsável pela mineralização dos ossos e pela supressão da secreção do hormônio paratireóide (Bondi, 1988).

$\mathrm{O}$ modo de ação do $1,25(\mathrm{OH})_{2} \mathrm{D}_{3}$ ainda não é muito compreendido, mas acredita-se que atue como hormônio esteróide através da síntese de RNAm. A 1,25 $\left(\mathrm{OH}_{2}\right) \mathrm{D}_{3}$ entra na célula e é transportada até a cromatina como um complexo de receptor-hormônio. O 
complexo e o RNA polimerase II combinam-se, resultando no aumento da síntese RNAm da proteína cálcio-ligante havendo aumento na síntese desta proteína, aumentando a capacidade de absorção de cálcio pelo enterócito (Bondi, 1988; Maynard et al., 1979).

A deficiência de vitamina D causa o raquitismo (em jovens) e a osteomalácia (em adultos). Dietas pobres em cálcio ou fósforo, ou mal balanceadas, também causam esses problemas (Blezinger, 2001; NIHCC, 2000; Stanton, 2001).

Os ossos da perna, ossos do tórax (distorção dos ossos do tórax) e ossos da coluna vertebral são diretamente afetados com a deficiência de vitamina D. Outras condições como casca mole dos ovos também são o resultado da deficiência de cálcio e fósforo (Roche, 2000; Blezinger, 2001; NIHCC, 2000).

O excesso de vitamina D também causa problemas como, depressão da performance, letargia, calcificação de tecidos moles, parada cardíaca, fadiga, problemas intestinais, enfraquecimento muscular, perda do apetite e excessiva micção (urinação). Excessos de 4-10 vezes a dose recomendada deve ser evitada (Roche, 2000; Stanton, 2001).

\subsection{Tipos de Cálcio Existentes no Plasma}

A concentração normal de cálcio no plasma é da ordem de 8,8 a 10,4 mg/dL. $40 \%$ do cálcio sanguiíneo total está ligado as proteínas plasmáticas, em especial a albumina. Os $60 \%$ restantes incluem o cálcio ionizado mais o cálcio complexado com fosfato e citrato. O cálcio total (que é a soma do cálcio ligado à proteína, mais o complexado e o ionizado) é usualmente determinado por análise clínicas laboratoriais do cálcio plasmático. O cálcio iozinado e o livre podem ser determinados, desde que estejam fisiologicamente na forma ativa do cálcio no plasma. Existia uma dificuldade de se medir o cálcio ionizado, assim não sendo rotineiramente medido. Atualmente o cálcio ionizado pode ser medido através de eletrodos íon-específicos. A fração de cálcio ionizado é geralmente medida a partir do cálcio plasmático total (Merck, 2001). 


\subsection{O Papel do Cálcio na Carne}

Segundo Nakamura (1973) e Taylor \& Etherington (1991), o íon cálcio é conhecido como um agente regulador do sistema contrátil, além de apresentar um papel importante no fenômeno de amaciamento da carne durante maturação pós-morte. Os íons cálcio removem especialmente as linhas- $Z$ das fibras musculares, enfraquecendo a força das fibras musculares e a sua concentração aumenta gradualmente durante a maturação pós-morte. Esse aumento, quando o nível de ATP intracelular cai abaixo de $0,1 \mathrm{mM}$ (normalmente com um pH perto de 6,2), parece ser devido a liberação de cálcio que estava ligado ao retículo sarcoplasmático e à mitocôndria. Nessas condições, íons cálcio podem ativar as calpaínas e tem sido observado que o enfraquecimento precoce pós-rigor das enzimas das fibras musculares é devido especialmente a proteólise dessas proteínas. Quando o $\mathrm{pH}$ ao redor de 5,5 é atingido, membranas lisossômicas são quebradas, liberando as enzimas catepsinas que também atuam no processo de amaciamento.

\subsection{Vitamina D: Requerimentos, Recomendações e Maciez da Carne}

Requerimento é a quantidade de um nutriente necessário para manter o animal em estado saudável, permitindo sua reprodução, produção de leite e ganho de peso quando o animal é criado em condições ambientais específicas. Recomendação é a quantidade de um nutriente que irá atingir os requerimentos para animais em condições ambientais menos definidas e rá incluir uma margem de segurança para as variações na ingestão, produção e disponibilidade do nutriente. A recomendação também deve considerar o custo do nutriente, o custo de sua deficiência, e o seu potencial para toxicidade (Weiss, 1998).

Segundo Weiss (1998) o custo anual de vitamina D para vacas leiteiras adultas (lactação de 305 dias e período seco de 60 dias) é de US\$ 0,60; sendo o seu requerimento de $30 \mathrm{UI} / \mathrm{kg}$ de peso vivo. 
Para bovinos de corte, o requerimento de vitamina D seria de 275 UI/kg de matéria seca. A UI é definida como sendo $0,025 \mu \mathrm{g}$ de colecalciferol ou seu equivalente (NRC, 1996).

Na década de 50, estudos mostraram que a febre do leite em vacas em lactação poderia ser prevenida pela elevação do nível de cálcio sanguiíneo através da suplementação com vitamina $D_{3}$ na dieta (Morgan, 1998a,b). O uso de vitamina $D_{3}$ para o amaciamento da carne é uma tecnologia recente, e consiste no fornecimento de médios a altos níveis da vitamina $\mathrm{D}_{3}$ por via oral.

Em trabalho realizado por Montegomery et al. (2002) a vitamina $D_{3}$ inibiu o ganho médio diário e a ingestão de matéria seca. A concentração de cálcio plasmático e muscular cresceu linearmente com a dose fornecida e a não foi influenciada pela dose de vitamina $\mathrm{D}_{3}$. A suplementação com vitamina $\mathrm{D}_{3}$ não influenciou nas características de qualidade e rendimento das carcaças e na atividade de calpastatina. A maciez e as características sensoriais foram afetas positivamente com a suplementação com vitamina $\mathrm{D}_{3}$. Assim, os autores concluíram que o tratamento com vitamina $\mathrm{D}_{3}$ efetivamente melhorou a maciez quando os animais apresentaram uma tendência de apresentarem carne menos macia e sem nenhum impacto em carne de animais com carne mais macia. A melhor dose de vitamina $\mathrm{D}_{3}$, que não influenciou as características da carcaça e o nível de resíduos nos tecidos e melhorou a maciez foi o de $0,5 \times 10^{6} \mathrm{UI} / \mathrm{an} / \mathrm{dia}$.

Em trabalho realizado por Karges et al. (2001), a ingestão de matéria seca foi menor para os animais suplementados com vitamina $D_{3}$ por 4 ou 6 dias consecutivos. O peso vivo e o peso da carcaça foram menores para animais suplementados com vitamina $D_{3}$. A dose de vitamina $D_{3}$ fornecido por 6 dias consecutivos antes do abate resultou em menores valores de força de cisalhamento, aumento da concentração de cálcio plasmático e não teve efeito do fornecimento de vitamina $\mathrm{D}_{3}$ sobre a análise sensorial.

Em novilhos e novilhas Brahman, Kotrla et al. (2001) mostraram que a suplementação com vitamina $\mathrm{D}_{3}$ elevou a concentração de cálcio sérico e que sua administração antes do 
abate, seguida de um período de 7 dias de alimentação normal, melhorou a maciez de carcaças desses bovinos.

Animais tratados com a vitamina $\mathrm{D}_{3}$ e seus metabólitos $\left(25(\mathrm{OH}) \mathrm{D}_{3}\right.$ e $\left.1,25(\mathrm{OH})_{2} \mathrm{D}_{3}\right)$ mostraram que a vitamina $\mathrm{D}_{3}$ foi mais eficaz na elevação da concentração dos metabólitos na carne, mas a administração dos metabólitos aumentou a concentração desses compostos no plasma. Para a maciez, a vitamina $\mathrm{D}_{3}$ e o metabólito $25(\mathrm{OH}) \mathrm{D}_{3}$ produziram bifes de contrafilé e coxão mole com menores valores de força de cisalhamento (Foote et al., 2001).

Novilhos tratados com $0,0.5,1$ ou $5 \times 10^{6}$ UI de vitamina $\mathrm{D}_{3}$, por um período de 7,8 e 9 dias de suplementação apresentaram maior concentração de cálcio subcelular da mitocôndria, de proteínas do retículo sarcoplasmático e maior concentração de fósforo miofibrilar. A dose de $5 \times 10^{6} \mathrm{UI}$ de vitamina $\mathrm{D}_{3}$, aumentou a quantidade de cálcio citosólico livre e fósforo ligado do retículo sarcoplasmático. $\mathrm{O}$ animais tratados com vitamina $\mathrm{D}_{3}$ tiveram maior mobilização do cálcio do sistema dos túbulos-T e maior deposição de cálcio ligado perto da linha-Z, o que resultou na redução dos valores de WBS e a melhora da maciez. Esta melhora na maciez de diversos cortes cárneos foi considerada uma excelente ferramenta na melhora da qualidade e na consistência de carne para varejo e fast food. Segundo Montgomery et al. (2001a,b) concluíram que a o melhor tratamento foi o de $0,5 \times 10^{6}$ UI de vitamina $\mathrm{D}_{3}$, por além de melhorar a maciez não afetou a performance dos animais e nem deixou resíduos no fígado.

Scanga et al. (2001) mostraram que animais tratados com uma combinação entre vitamina $\mathrm{D}_{3}$ e carbonato de cálcio $\left(\mathrm{CaCO}_{3}\right)$ tiveram redução no peso vivo final, no ganho de peso diário e na ingestão de alimentos. A redução do consumo de alimentos pelos animais foi considerada como sendo um indicativo de toxicidade aos níveis supranutricionais de vitamina $\mathrm{D}_{3}$ fornecidos. Houve um aumento na concentração de cálcio sérico total, demonstrando assim a efetividade da vitamina $\mathrm{D}_{3}$ em manipular a concentração de cálcio circulante. Não foi observado efeito do tratamento com vitamina $D_{3}$ na força de cisalhamento, o que diferiu de outros trabalhos já realizados. 
Segundo Rentfrow et al. (2001), novilhas suplementadas com altos níveis de vitamina $\mathrm{D}_{3}$ ou com uma mistura entre vitamina $\mathrm{D}_{3}$ e vitamina $\mathrm{E}$ apresentaram uma elevação na concentração de cálcio sérico, mas não apresentaram redução na força de cisalhamento.

Usando-se a vitamina $\mathrm{D}_{3}$ em cordeiros com gene callipyge, Wiegand et al. (1998, 2001) observaram que níveis entre 500.000 e $2 \times 10^{6}$ UI de vitamina $D_{3}$ e suplementação por 5 ou 7 dias antes do abate não foram suficientes para melhorar a maciez (reduzir os valores de força de cisalhamento) do músculo Longissiumus .

Com a hipótese que a vitamina $D_{3}$ aumentaria o amaciamento da carne, através do aumento os níveis de cálcio no tecido, sendo assim ativadas as enzimas proteolíticas que degradam certas proteínas musculares, Berry et al. (2000) trataram novilhos com 6x106 UI de vitamina $\mathrm{D}_{3}$ por um período de 7 dias antes do abate. Em seus resultados foram observados que, a ingestão de matéria seca foi reduzida nos animais tratados com a vitamina $D_{3}$, sendo que a redução da ingestão de matéria seca resultou em diminuição do ganho diário e da relação ganho:consumo; os novilhos tiveram menor maturidade esquelética; as carnes de animais tratados com vitamina $\mathrm{D}_{3}$ foram menos macias; aumentou a concentração de cálcio sérico e que, mesmo retirando-se a vitamina da dieta 2 dias antes do abate esta concentração ainda permaneceu elevada.

Em trabalho de Boleman et al. (2000), a utilização de uma suplementação com 750.000 UI de vitamina $\mathrm{D}_{3}$, por um período de 4 dias antes do abate resultou em maiores níveis de vitamina $\mathrm{D}_{3}$ no fígado, não mostrou diferenças nos níveis de cálcio ionizável do sangue, melhorou a maciez da carne, houve uma menor espessura de gordura em carcaças de animais tratados com vitamina $\mathrm{D}_{3}$ e com escore geral de conformação (OCS) maior para a vitamina $\mathrm{D}_{3}$.

Segundo Enright et al. (2000a,b), em suínos a vitamina $D_{3}$ reduziu o ganho de peso diário, a proporção ganho:alimento, o peso vivo ao abate e o peso da carcaça, aumentou a concentração de cálcio sérico, melhorou a coloração do músculo e da capacidade de retenção de água, e não afetou o rendimento. 


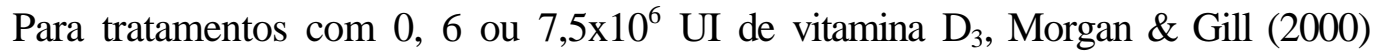
mostraram que houve um aumento da concentração de cálcio intramuscular, melhora da maciez da carne e maior atividade proteolítica das calpaínas.

Montegomery et al. (2000a,b) mostraram um aumento da concentração de cálcio plasmático de 150 a 170 vezes quando do fornecimento de 5,0 ou 7,5 milhões de UI de vitamina $D_{3}$. Foi também observado aumento na concentração de vitamina $D_{3}$ no fígado (71114 vezes) e rim (24-27 vezes). A suplementação com vitamina $D_{3}$ melhorou a maciez da carne (reduziu o valor de força de cisalhamento) e não afetou a análise sensorial feita nas carnes contra-filé, a cor e os graus de rendimento e qualidade. Pelo teste de Western blotting foi observado um maior aparecimento do componente $30 \mathrm{kDa}$, como resultado da degradação da troponina-T pela calpaína. Também foi observada redução do ganho médio diário (pela diminuição da ingestão de alimentos), quando os animais foram tratados com $5 \times 10^{6}$ UI de vitamina $\mathrm{D}_{3}$. Doses menores de vitamina $\mathrm{D}_{3}$ não afetaram negativamente o ganho médio diário, a ingestão de alimentos e as características de carcaça.

Através da caracterização da degradação muscular, Montgomery et al. (2000c) mostraram que em algumas raças a maior concentração de vitamina $\mathrm{D}_{3}$ na suplementação deve funcionar como um mecanismo secundário no músculo para aumentar a degradação da proteína muscular.

Segundo Ribeiro (2000), o uso de vitamina $\mathrm{D}_{3}$ (na quantidade e no período utilizado) foi insuficiente para causar alterações na maciez da carne.

Em vacas para descarte, a suplementação com vitamina $D_{3}$ aumentou a concentração de cálcio muscular, melhorou os valores de força de cisalhamento (maciez) e não afetou a análise sensorial (Rider et al., 2000).

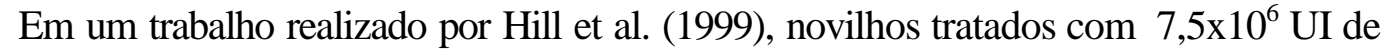
vitamina $\mathrm{D}_{3}$ por um período de 10 dias antes do abate apresentaram um aumento na concentração de cálcio muscular, com pouca diferença na concentração de cálcio, magnésio e fósforo plasmático, sem diferenças entre os valores da atividade de calpastatina e força de 
cisalhamento, redução da ingestão de matéria seca em 14\%; concluindo-se então que altos níveis de vitamina $\mathrm{D}_{3}$ em curtos períodos de fornecimento não é um método eficaz de melhorar a maciez da carne.

Trabalhos de Karges et al. (1999a,b,c,d) com suplementação de altos níveis de vitamina $D_{3}$, para novilhos, resultou em um aumento na concentração de cálcio e fósforo plasmático, aumento do $\mathrm{pH}$ muscular, redução na concentração de magnésio plasmático, redução no peso da carcaça e peso vivo dos animais (em decorrência da redução na ingestão de matéria seca), aumento na maciez de bifes de contra-filé e sem diferenças na atividade de calpastatina. A partir desses resultados foi concluído que, a associação entre o aumento do pH muscular e a concentração de cálcio deve ter influenciado o processo de amaciamento pós-morte; que a vitamina $\mathrm{D}_{3}$ alterou os padrões de ingestão e reduziu a ingestão de alimentos quando a quantidade total de vitamina $D_{3}$ ingerida nos primeiros dias excederam aproximadamente $30 \mathrm{UI}$.

Animais tratados com $6 \times 10^{6}$ UI de vitamina $\mathrm{D}_{3}$ por um período de 4 ou 6 dias antes do abate, reduziram a ingestão de matéria seca a partir do $5^{\circ}$ dia de suplementação, o que motivou a redução do período de fornecimento da vitamina $\mathrm{D}_{3}$. O peso vivo, parâmetros do peso da carcaça, área do olho do lombo, espessura de gordura e grau de rendimento não foram afetados quando o fornecimento da vitamina $\mathrm{D}_{3}$. O grau de qualidade (quality grade) melhorou em $20 \%$. A concentração de vitamina $\mathrm{D}_{3}$ no fígado, rim e músculo foi aumentada. E não houve diferenças na maciez da carne (Meredith \& Morgan, 1999; Morgan et al., 1999).

Novilhos tratados com doses de $0,0.5,1,2.5,5$ ou $7.5 \times 10^{6} \mathrm{UI}$ de vitamina $\mathrm{D}_{3}$ por um período de 8 dias antes do abate mostraram resultados de elevação da concentração de cálcio plasmático (quanto maior a dose de vitamina, maior a concentração de cálcio plasmático). Resíduos de vitamina $\mathrm{D}_{3}$ e seus metabólicos foram encontrados no fígado e na carne, a partir da dose de $1 \times 10^{6}$ UI de vitamina $\mathrm{D}_{3}$ (Montgomery et al., 1999a,b).

Segundo Vargas et al. (1999a,b) o tratamento com vitamina $\mathrm{D}_{3}$ sozinho ou em conjunto com a vitamina E resultaram em animais mais pesados. Para animais tratados com 
vitamina $\mathrm{D}_{3}$, o ganho de peso médio diário (GMPD) foi menor para animais tratados com vitamina $\mathrm{D}_{3}$ e a ingestão de matéria seca (IMS) foi similar para todos os tratamentos. A redução do GMPD foi devido a uma redução da ingestão de alimentos, como um resultado de uma hipercalcemia (elevação dos níveis de cálcio sérico) causada pela suplementação com a vitamina. Ainda foram observados maiores graus de rendimento (yield grade), aceleração do processo de maturação e melhora da maciez da carne de animais tratados com vitamina $\mathrm{D}_{3}$.

Em 1999(a,b), Swanek et al. realizaram três experimentos usando animais mestiços Angus, Hereford, Chrarolês e Brangus, e estudando diferentes níveis de cálcio $(0,2.5,5.0$, 7.0 milhões de UI de vitamina $\mathrm{D}_{3}$ ) e tempos de suplementação (7 ou 10 dias antes do abate). No experimento 1, observou-se que uma suplementação com 7,5 milhões de UI de vitamina $\mathrm{D}_{3}$ durante 10 dias resultou em um aumento da concentração de cálcio plasmático (8-48\%). No experimento 2, uma suplementação durante 7 dias com $5 \times 10^{6}$ UI de vitamina $\mathrm{D}_{3} \mathrm{e}$ maturação da carne por 7 dias reduziu a força de cisalhamento $(0,58 \mathrm{~kg})$ e melhorou a taxa de maciez sensorial (0,6 unidades). E no experimento 3, uma suplementação com 7,5x10 6 UI de vitamina $D_{3}$ durante 10 dias resultou em um aumento na concentração de cálcio plasmático e muscular, melhorou a maciez em cortes maturados por 7 e 14 dias e a maciez sensorial. Com esses experimentos, concluiu-se que a elevação da concentração de cálcio muscular, como resultado da suplementação com vitamina $\mathrm{D}_{3}$, pareceu ser o responsável pelo amaciamento da carne provavelmente devido a pronta ativação das proteases cálcio-dependentes (calpaínas).

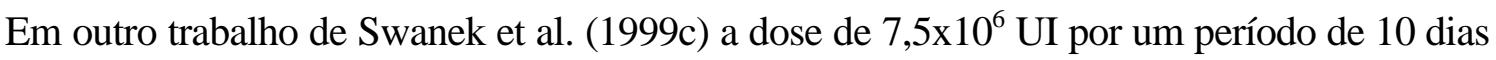
antes do abate causou elevação da concentração de cálcio muscular, reduziu os valores de força de cisalhamento em $18 \%$ e reduziu a atividade de $\mu$ - e m-calpaína com 24 horas de pós-mortem, o que indica que a suplementação com vitamina $\mathrm{D}_{3}$ aumentou a concentração de cálcio muscular o bastante para ativar e acelerar o processo de amaciamento.

Segundo Enright et al. (1998a,b), a suplementação com altos níveis de vitamina $D_{3}$ durante 10 dias antes do abate resultou em um aumento na concentração de cálcio sangüíneo, melhorou a coloração e a capacidade de retenção da água do lombo, reduziu a ingestão de 
alimento e a taxa de crescimento, e não apresentou nenhum efeito sobre a palatabilidade do produto final.

Em um resumo de sete trabalhos, escrito por Morgan (1998a,b), o fornecimento de vitamina $\mathrm{D}_{3}$ aumenta em 30-40\% a concentração de cálcio muscular; sendo este nível de cálcio o suficiente para ativar o sistema de amaciamento das proteases cálcio-dependentes (calpaínas), resultando na redução da dureza da carne em até $50 \%$.

Montgomery et al. (1998) mostraram que a suplementação com vitamina $D_{3}(5$ ou $7,5 \times 10^{6}$ UI de vitamina $\mathrm{D}_{3}$ por um período de 9 dias antes do abate) aumentou a concentração de cálcio plasmático e cálcio muscular e melhorou a maciez da carne.

Trabalhando com suínos, Sparks et al. (1998) realizou 3 experimentos utilizando diferentes doses e tempos de fornecimento de vitamina $\mathrm{D}_{3}$ antes do abate. Para os animais tratados com a vitamina $\mathrm{D}_{3}$ foram observadas elevação na concentração de cálcio no plasma; sem diferenças nas características de rendimento da carcaça; aumento do $\mathrm{pH}$ final da carcaça; sem diferenças na coloração, firmeza, marmoreio ou pH do lombo (com 1, 7, 14 ou 21 dias de maturação pós-morte) e sem melhora na maciez da carne (medida pelo Warner Braztler Shear e Star Probe).

Em trabalho escrito por Beitz et al. (1997), a carne de animais tratados com vitamina $\mathrm{D}_{3}$ teve menores valores de força de cisalhamento, sugerindo assim que a suplementação com vitamina $\mathrm{D}_{3}$ melhora a maciez em todos os tempos de maturação. Este resultado foi confirmado através da realização do teste de Western blotting, que detectou aumento do aparecimento do componente $30 \mathrm{kDa}$, resultado da maior degradação da troponina-T pela calpaína.

Swanek et al. (1997) observaram que a dose de $5 \times 10^{6}$ UI, por um período de 5 dias antes do abate reduziu a força de cisalhamento em 6,6\% (após 7 dias de maturação) e a dose $7,5 \times 10^{6} \mathrm{UI}$, por um período de 10 dias reduziu a força de cisalhamento em $18 \%$. Estes resultados foram devido a elevação do cálcio plasmático (10,39 mg/dL X 9,23 mg/dL) e a redução do magnésio plasmático (1,88 meq/dL X 1,46 meq/dL). 


\subsection{Resíduos de Vitamina $\mathrm{D}_{3}$ e Saúde Humana}

Apesar da vitamina $D_{3}$ parecer ser uma nova ferramenta a ser utilizada para o amaciamento pré-abate da carne, a ingestão de níveis elevados de vitamina $\mathrm{D}_{3}$, por longos períodos de tempo, pode causar alguns efeitos negativos como redução da ingestão de alimentos e taxa de crescimento pelos bovinos. Em humanos, o consumo da carne, do fígado e do rim de animais tratados com altos níveis de vitamina $D_{3}$ podem causar alguns distúrbios no metabolismo de cálcio, podendo ser prejudicial a saúde (Dikeman et al., 2000).

Em trabalho de Foote et al. (2001), animais tratados com a vitamina D e seus metabólitos $\left(25(\mathrm{OH}) \mathrm{D}_{3}\right.$ e $\left.1,25(\mathrm{OH})_{2} \mathrm{D}_{3}\right)$ mostraram o aparecimento de uma quantidade substancial de resíduo de vitamina $\mathrm{D}_{3}$ e $25(\mathrm{OH}) \mathrm{D}_{3}$ e pouca da forma ativa hormonal $1,25(\mathrm{OH})_{2} \mathrm{D}_{3}$ na carne.

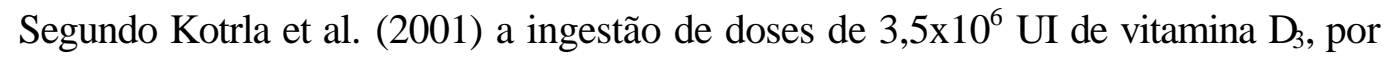
um período de 6 ou 13 dias de suplementação, resultou em um aumento na concentração de vitamina $\mathrm{D}_{3}$ no fígado de $280 \%$. Quando, após a suplementação, os animais permanecem por um período de 7 dias sem a vitamina $\mathrm{D}_{3}$, a sua concentração no fígado voltou ao normal.

Bifes de animais tratados com vitamina $\mathrm{D}_{3}$ apresentaram de 78 a 91 ng de vitamina $\mathrm{D}_{3}$ /grama o que é aproximadamente 24 vezes a mais que a concentração do controle. A exigência diária de adultos é de $10 \mu \mathrm{g}$ (NRC, 1989). Desse modo, para se consumir $80 \mathrm{ng}$ de vitamina $\mathrm{D}_{3} /$ grama seria necessário a ingestão de $125 \mathrm{~g}$ de bife de strip loin ou top round para atingir essa exigência, ou ainda consumindo $16,4 \mathrm{~g}$ de fígado de animais tratados com 5 milhões de UI de vitamina $\mathrm{D}_{3}\left(610 \mathrm{ng}\right.$ vitamina $\left.\mathrm{D}_{3} / \mathrm{g}\right)$. O cozimento do fígado a $75{ }^{\circ} \mathrm{C}$ resultou em uma redução de 10-30\% nas concentrações de vitamina $D_{3}$ (Montgomery et al., 1999b; 2000a; 2002). 


\section{MATERIAL E MÉTODOS}

\subsection{Animais}

Foram utilizados 36 animais machos, castrados e da raça Nelore. Estes animais eram provenientes de um rebanho particular e permaneceram em piquetes de $7 \mathrm{~m}^{2}$, com dois animais por piquete, pelo período de 20 dias antes do abate no Instituto de Zootecnia de Brotas, onde receberam os tratamentos com vitamina $\mathrm{D}_{3}$.

\subsection{Tratamentos}

Os tratamentos foram preparados no Departamento de Zootecnia, da Escola Superior de Agricultura "Luiz de Queiroz", em Piracicaba, SP.

Aos animais foi fornecido 0, 3, 6 e 9 milhões de UI de vitamina D/animal/dia, utilizando-se ROVIMIX ${ }^{\circledR} \mathrm{D}_{3} 500$ da Roche, em um período de dez dias antes do abate. O fornecimento foi feito por via oral, misturado ao concentrado.

\subsection{Abate}

Antes do abate os animais foram pesados para registro do peso vivo (PV). Após o abate (moblização, atordoamento, sangria, esfola, evisceração e separação do corpo do animal em duas 1/2 carcaças), a carcaça foi pesada quente (PCQ); em seguida as 1/2 carcaças foram resfriadas por um período de $24 \mathrm{hs}$ em câmara fria $\left(0-4^{\circ} \mathrm{C}\right)$. Vinte e quatro horas após o abate e terem ficado sob refrigeração $\left(0-4^{\circ} \mathrm{C}\right)$, as carcaças foram pesadas para obtenção do peso da carcaça resfriada (PCR) e o pH determinado. A área do olho do lombo (AOL) foi medida entre a $12^{-}-13^{\mathrm{a}}$ costela, no lado esquerdo da carcaça, utilizando um grid de plástico (padrão USDA) quadriculado com 10 quadrados por cada 2,54 $\mathrm{cm}^{2}$. A espessura da gordura (EG) foi medida na altura da $12^{\underline{a}-13^{\underline{a}}}$ costela, no lado esquerdo da carcaça, com uma régua graduada específica para a medição da gordura. Foram ainda estimadas as porcentagens de carcaça quente e resfriada (RQ e RF). De cada animal abatido foram retiradas porções entre a $12^{\mathrm{a}}$ costela e a $5^{\mathrm{a}}$ vértebra lombar, que serviram para a avaliação da 
maciez e testes de cozimento, obtendo-se valores da força de cisalhamento (WBSF), porcentagem de perdas por evaporação (PPE), perdas por gotejamento (PPG) e perdas totais (PPT). Além disso, uma porção de carne de mesma localização foi utilizada para determinação da concentração de cálcio, magnésio, fósforo, sódio e potássio.

\subsection{Força de Cisalhamento e Perdas por Cozimento}

Segundo recomendações do Meat Animal Research Center, Clay Center, NE, USDA (procedimento padrão seguido por laboratórios certificados para analisar a maciez da carne de bovinos em programas de melhoramento genético) e AMSA (1978) foram realizados os seguintes procedimentos para a análise da força de cisalhamento e perdas por cozimento:

1) Após o período de resfriamento da carcaça por 24 horas em câmara fria $\left(4^{\circ} \mathrm{C}\right)$, bifes de $2,5 \mathrm{~cm}$ de espessura do músculo Longissimus dorsi (contra-filé), entre a $12^{-}$ costela e a $5^{a}$ vértebra lombar (lado esquerdo), sem osso e sem excesso de gordura foram retiradas, embaladas a vácuo e transferidas para um câmara fria $\left(0-3^{\circ} \mathrm{C}\right)$ onde permaneceram em maturação por 1,8 e 15 dias, e depois congeladas a $\left(-20^{\circ} \mathrm{C}\right)$ para posterior análise da força de cisalhamento e das perdas por cozimento;

2) Os bifes de $2,5 \mathrm{~cm}$ de espessura, congelados e maturados por 1, 8 e 15 dias após o abate, foram descongelados a temperatura de $2-5^{\circ} \mathrm{C}$ até que a temperatura interna fosse de $2-5^{\circ} \mathrm{C}$ (período de descongelamento entre 24-36 hs);

3) Após atingirem temperatura interna entre $2-5^{\circ} \mathrm{C}$, os bifes foram assados (no máximo quatro amostras de cada vez) em forno elétrico (pré-aquecido a $170^{\circ} \mathrm{C}$ ) até a temperatura interna atingir $71^{\circ} \mathrm{C}$ (o monitoramento da temperatura foi feito com termômetros especiais, colocados no centro geométrico de cada bife);

4) Os bifes foram pesados antes e depois do cozimento para a determinação da porcentagem de perdas por cozimento;

5) Os bifes foram resfriados à temperatura ambiente e colocados na geladeira a $2-5^{\circ} \mathrm{C}$ (de um dia a outro) antes de serem removidas pequenas amostras cilíndricas; 
6) Após o resfriamento foram removidas seis a oito amostras cilíndricas de 1,27 cm de diâmetro, paralelamente à orientação das fibras musculares e sendo essas amostras conservadas em geladeira até a medição da força de cisalhamento;

7) Para a análise da força de cisalhamento utilizou-se de um aparelho Warner Bratzler Shear Force Device ou outro aparelho com célula WB acoplada e velocidade fixada a $20 \mathrm{~cm} / \mathrm{min}$.

\subsection{Análise Sensorial}

A análise sensorial foi realizada no Laboratório de Análises Sensoriais do Departamento de Tecnologia de Alimentos da ESALQ-USP, seguindo-se os procedimentos do AMSA (1978), onde:

1) Utilizou-se bifes de $2,5 \mathrm{~cm}$ de espessura do músculo Longissimus dorsi (contrafilé), entre a $12^{\mathrm{a}}$ costela e a $5^{\mathrm{a}}$ vértebra lombar (lado esquerdo), sem osso e sem excesso de gordura;

2) $\mathrm{O}$ procedimento de cozimento da carne foi o mesmo apresentado para a determinação da força de cisalhamento;

3) Foram utilizadas 50 pessoas (provadores) independentes;

4) A esses provadores foi fornecida uma ficha de avaliação, que constava de uma escala hedônica de 8 pontos para maciez, suculência, sabor e avaliação geral;

5) A avaliação estatística dos resultados da análise sensorial foi feita através do programa SAS (1990), seguindo modelo estatístico inteiramente casualizado, envolvendo quatro tratamentos $\left(0,3,6\right.$ e $9 \times 10^{6}$ UI vitamina $\left.D_{3} / a n / d i a\right)$ e 50 repetições (provadores). Aplicou-se a técnica de análise de variância para comparação de médias dos tratamentos, uma vez que as pressuposições para uso da técnica ANOVA foram satisfeitas.

3.6 Análise de Minerais para Sangue e Carne 
A coleta de amostras de sangue foi feita no dia do abate, quando da exposição da veia jugular do animal. Nessas amostras foram observadas as concentrações de cálcio, magnésio, fósforo, sódio, potássio e glicose.

A análise da concentração de minerais nas amostras de sangue e carne foram realizadas no Laboratório de Análise de Solos da USP-ESALQ e no Laboratório de Nutrição Animal do Centro de Energia Nuclear na Agricultura (CENA - USP), em Piracicaba, utilizando-se da metodologia de absorção atômica para a quantificação desses minerais.

A análise de glicose foi realizada no Laboratório de Bromatologia do Departamento de Zootecnia, na ESALQ - USP.

\subsection{Análise Estatística}

Utilizou-se de um delineamento inteiramente casualizado, envolvendo 4 tratamentos ( 0 , 3, 6 e 9 milhões de UI de vitamina $\mathrm{D}_{3}$ ) e 9 repetições (totalizando 36 animais). Por meio de um esquema de regressão polinomial se obteve equações que descrevessem o comportamento das variáveis: peso vivo, peso da carcaça quente, peso da carcaça resfriada, $\mathrm{pH}$, área do olho do lombo, espessura da gordura, porcentagens de carcaça quente e resfriada, concentrações de cálcio, magnésio, fósforo, sódio e potássio na carne e no plasma e glicose plasmático, considerando-se os valores de cada repetição para cada tratamento. Para as variáveis força de cisalhamento, porcentagem de perdas por evaporação, perdas por gotejamento, perdas totais e análise sensorial foi adotado um esquema de parcelas subdivididas, tendo-se para as parcelas as 4 doses de vitamina $D_{3}(0,3,6$ e 9 milhões de UI) e para as sub-parcelas os 3 períodos de maturação ( 1,8 e 15 dias). 


\section{RESULTADOS E DISCUSSÃO}

\subsection{Características da Carcaça}

Não foram encontradas diferenças significativas para as principais características da carcaça (Tabela 1).

As características de espessura da gordura (EG), espessura de gordura/100 kg carcaça esfriada (EG/100), temperatura às 0 hs (T0), porcentagem do dianteiro (PD) e porcentagem de ponta de agulha (PPA) foram significativas a 5\% (Tabela 2). Observa-se que para as características EG e EG/100, esta diferença foi devida principalmente a grande variabilidade entre as EG dos animais (mínimo de 1 e máximo de 8 milímetros). Para a T0, a diferença entre os tratamentos para a tomada da temperatura inicial foi devido a grande diferença de tempo na obtenção dos resultados, onde a T0 foi considerada aquela tomada quando do abate do último animal, e assim tendo uma diferença significativa na temperatura para o primeiro animal abatido $( \pm 1$ hora de diferença entre a primeira e a última carcaça). Para a PD e PPA, os resultados obtidos não apresentam justificativa da sua ocorrência. 
Tabela 1. Valores médios das características de carcaças de animais Bos indicus suplementados com vitamina $\mathrm{D}_{3}$ por 10 dias consecutivos antes do abate

\begin{tabular}{lccc}
\hline Característica $^{1}$ & Média & CV $(\%)$ & Pr > F \\
\hline PV $(\mathrm{kg})$ & 511,46 & 7,31 & 0,43 \\
PCQ $(\mathrm{kg})$ & 265,96 & 6,93 & 0,47 \\
RQ $(\%)$ & 52,00 & 3,30 & 0,27 \\
PCR $(\mathrm{kg})$ & 268,31 & 6,89 & 0,49 \\
RF $(\%)$ & 52,50 & 6,70 & 0,35 \\
TE $(\mathrm{kg})$ & 126,76 & 7,08 & 0,74 \\
PTE $(\%)$ & 47,24 & 1,53 & 0,21 \\
D5C $(\mathrm{kg})$ & 104,19 & 6,97 & 0,07 \\
PA $(\mathrm{kg})$ & 42,64 & 7,90 & 0,23 \\
AOL $\left(\mathrm{cm}{ }^{2}\right)$ & 61,36 & 10,46 & 0,23 \\
AOL/100 & 22,95 & 11,34 & 0,51 \\
T24 $\left({ }^{\circ} \mathrm{C}\right)$ & 10,30 & 10,13 & 0,23 \\
pH0 & 7,04 & 3,21 & 0,81 \\
pH24 & 6,12 & 6,44 & 0 \\
\hline
\end{tabular}

$\mathrm{PV}=$ peso vivo, $\mathrm{PCQ}=$ peso da carcaça quente, ${ }^{1} \mathrm{RQ}=$ rendimento quente, $\mathrm{PCR}=$ peso da carcaça resfriada, $\mathrm{RF}=$ rendimento frio, $\mathrm{TE}=$ traseiro especial, $\mathrm{PTE}=$ porcentagem do traseiro especial, $\mathrm{D} 5 \mathrm{C}=$ dianteiro com 5 costelas, $\mathrm{PA}=$ ponta de agulha, $\mathrm{AOL}=$ área do olho do lombo, $\mathrm{AOL} / 100=\mathrm{AOL} / 100 \mathrm{~kg}$ carcaça resfriada, $\mathrm{T} 24=$ temperatura $24 \mathrm{hs}, \mathrm{pH} 0=\mathrm{pH} 0 \mathrm{hs}, \mathrm{pH} 24=\mathrm{pH} 24 \mathrm{hs}$.

Segundo Scanga et al. (2001), Berry et al. (2000), Enright et al. (2000a,b), Montegomery et al. (2002; 2000a,b), Karges et al. (1999a,b,c,d), Meredith \& Morgan (1999), Morgan et al. (1999), Enright et al. (1998a,b) e Sparks et al. (1998), o fornecimento de altas doses de vitamina $D_{3}$ fez com que os animais tivessem menor PV final e ganho de peso diário (GPD), devido a redução da ingestão de alimento (indicando início de intoxicação 
pelos níveis supranutricionais de vitamina $\mathrm{D}_{3}$ fornecidos). $\mathrm{O}$ não fornecimento, ou doses menores de vitamina $\mathrm{D}_{3}$ não afetaram as variáveis estudadas, nem as características da carcaça. Entretanto para Vargas et al. (1999a,b) o tratamento com vitamina $\mathrm{D}_{3}$ sozinho ou em conjunto com a vitamina $\mathrm{E}$ resultou em animais mais pesados, mas o GPD foi menor para animais tratados com vitamina $\mathrm{D}_{3}$ e a ingestão de matéria seca (IMS) foi similar para todos os tratamentos.

Apesar dos resultados não apresentarem diferença significativa entre as doses estudadas, observa-se que o $\mathrm{pH} 24$ apresentou um valor numericamente alto, o que concorda com Karges et al. (999), que também observaram um pH final elevado. Já, Karges et al. (2001), relataram que o $\mathrm{pH} 24$ de animais tratados com vitamina $\mathrm{D}_{3}$ foram menores do que em animais controle.

Tabela 2. Média dos quadrados mínimos (LSM) e erro padrão (EP) das características de carcaça com significância de 5\% para animais Bos indicus suplementados com vitamina $\mathrm{D}_{3}\left(\right.$ dose $\left.\mathrm{X} 10^{6} \mathrm{UI} / \mathrm{an} / \mathrm{dia}\right)$ por 10 dias consecutivos antes do abate

\begin{tabular}{|c|c|c|c|c|c|c|c|c|c|c|}
\hline \multirow{3}{*}{ Dose } & \multicolumn{10}{|c|}{ Características $^{1}$} \\
\hline & \multicolumn{2}{|c|}{$\mathrm{EG}\left(\mathrm{cm}^{2}\right)$} & \multicolumn{2}{|c|}{ EG/100 } & \multicolumn{2}{|c|}{$\mathrm{T} 0\left({ }^{\circ} \mathrm{C}\right)$} & \multicolumn{2}{|c|}{$\mathrm{PD}(\%)$} & \multicolumn{2}{|c|}{$\operatorname{PPA}(\%)$} \\
\hline & LSM & SE & LSM & $\mathrm{SE}$ & LSM & $\mathrm{SE}$ & LSM & SE & LSM & SE \\
\hline 0 & 3,38 & 0,66 & 1,26 & 0,24 & 32,09 & 0,43 & 38,66 & 0,30 & 15,84 & 0,27 \\
\hline 3 & 3,88 & 0,66 & 1,39 & 0,24 & 34,08 & 0,43 & 39,55 & 0,30 & 15,78 & 0,27 \\
\hline 6 & 5,60 & 0,59 & 2,13 & 0,21 & 33,86 & 0,39 & 37,96 & 0,27 & 16,62 & 0,24 \\
\hline 9 & 3,40 & 0,59 & 1,26 & 0,21 & 33,21 & 0,39 & 39,24 & 0,27 & 15,33 & 0,24 \\
\hline
\end{tabular}

${ }^{1} \mathrm{EG}=$ espessura da gordura, EG/100 $=\mathrm{EG} / 100 \mathrm{~kg}$ carcaça resfriada, $\mathrm{T} 0=$ temperatura $0 \mathrm{hs}, \mathrm{PD}=$ porcentagem do dianteiro, PPA= porcentagem de ponta de agulha.

LSM = Média dos quadrado mínimos.

$\mathrm{SE}=$ Erro padrão. 
Tabela 3. Contrastes lineares para as características de carcaça de animais Bos indicus suplementados com vitamina $\mathrm{D}_{3}$ por 10 dias consecutivos antes do abate

Contrastes Significativos

Características $^{1} \quad$ Efeito Geral Efeito Grau 1 Efeito Grau 2 Efeito Grau 3

\begin{tabular}{|c|c|c|c|c|}
\hline $\mathrm{PV}(\mathrm{kg})$ & NS & NS & NS & NS \\
\hline PCQ (kg) & NS & NS & NS & NS \\
\hline RQ (\%) & NS & NS & NS & NS \\
\hline PCR (kg) & NS & NS & NS & NS \\
\hline $\mathrm{RF}(\%)$ & NS & NS & NS & NS \\
\hline TE (kg) & NS & NS & NS & NS \\
\hline PTE (\%) & NS & NS & NS & NS \\
\hline D5C (kg) & NS & NS & NS & $*$ \\
\hline $\mathrm{PD}(\%)$ & $* *$ & NS & NS & $* *$ \\
\hline PA (kg) & NS & NS & NS & NS \\
\hline PPA (\%) & $* *$ & NS & $*$ & $*$ \\
\hline $\mathrm{AOL}\left(\mathrm{cm}^{2}\right)$ & NS & NS & NS & NS \\
\hline AOL/100 & NS & NS & NS & NS \\
\hline $\mathrm{EG}(\mathrm{cm})$ & $*$ & NS & $*$ & NS \\
\hline EG/100 & $*$ & NS & $*$ & $*$ \\
\hline $\mathrm{T} 0\left({ }^{\circ} \mathrm{C}\right)$ & $*$ & NS & $* *$ & NS \\
\hline $\mathrm{T} 24\left({ }^{\circ} \mathrm{C}\right)$ & NS & NS & NS & NS \\
\hline pH0 & NS & NS & NS & NS \\
\hline pH24 & NS & $*$ & NS & NS \\
\hline
\end{tabular}

$\mathrm{PV}=$ peso vivo, $\mathrm{PCQ}=$ peso da carcaça quente, $\mathrm{RQ}=$ rendimento quente, $\mathrm{PCR}=$ peso da carcaça resfriada, $\mathrm{RF}=$ rendimento frio, $\mathrm{TE}=$ traseiro especial, $\mathrm{PTE}=$ porcentagem do traseiro especial, $\mathrm{D} 5 \mathrm{C}=$ dianteiro com 5 costelas, $\mathrm{PD}=$ porcentagem do dianteiro, $\mathrm{PA}=$ ponta de agulha, $\mathrm{PPA}=$ porcentagem de ponta de agulha, $\mathrm{AOL}=$ área do olho do lombo, $\mathrm{AOL} / 100=\mathrm{AOL} / 100 \mathrm{~kg}$ carcaça resfriada, $\mathrm{EG}=$ espessura da gordura, EG/100 $=\mathrm{EG} / 100 \mathrm{~kg}$ carcaça resfriada, $\mathrm{T} 0=$ temperatura $0 \mathrm{hs}, \mathrm{T} 24=$ temperatura $24 \mathrm{hs}, \mathrm{pH} 0=\mathrm{pH} 0 \mathrm{hs}, \mathrm{pH} 24=\mathrm{pH} 24$ hs.

${ }^{a} \mathrm{NS}=$ não significativo $(\mathrm{P}>0,05)$.

$* \mathrm{P}(<0,05)$.

** $\mathrm{P}(<0,01)$.

\subsection{Teor de Glicose no Plasma}


A glicose plasmática (Tabela 4) não apresentou diferença significativa $(\mathrm{P}>0,05)$ entre as doses de vitamina $\mathrm{D}_{3}$ estudadas. Observa-se pequena queda na concentração de glicose plasmática para a dose $6 \times 10^{6} \mathrm{UI} / \mathrm{an} / \mathrm{dia}$, enquanto que para as demais doses houve um ligeiro aumento.

Estes dados são semelhantes aos encontrados por Swanek et al. (1999a,b; 1997).

Tabela 4. Média dos quadrados mínimos (LSM) e erro padrão (EP) do teor de glicose para animais Bos indicus suplementados com vitamina $\mathrm{D}_{3}$ por 10 dias consecutivos antes do abate

\begin{tabular}{ccc}
\hline Dose & \multicolumn{2}{c}{ Glicose $(\mathrm{mg} / \mathrm{dL})$} \\
$(\mathrm{x} \mathrm{10}$ UI/an/dia $)$ & LSM & EP \\
\hline 0 & 255,10 & 42,85 \\
3 & 266,96 & 41,20 \\
6 & 209,57 & 39,25 \\
9 & 273,53 & 36,88 \\
\hline
\end{tabular}

Média geral= 250,21; CVgeral=46,51\%; Pr $>$ Fgeral $=0,74$

LSM = Média dos quadrado mínimos

$\mathrm{SE}=$ Erro padrão

\subsection{Concentração de Minerais no Plasma}

Para as concentrações de cálcio, sódio, potássio e magnésio no plasma (Tabela 5) não foram encontradas diferenças $(\mathrm{P}>0,05)$ entre as doses estudadas.

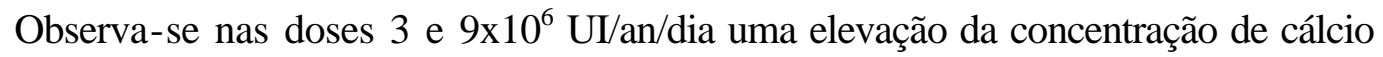
em apenas 6,98\%, o que não foi alto o suficiente para se ter uma diferença marcante na concentração de cálcio de animais tratados com vitamina $\mathrm{D}_{3}$. Este resultado é o contrário dos apresentados por Karges te al. (2001), Kotrla et al. (2001), Scanga et al. (2001), Rentfrow et al. (2001), Berry et al. (2000), Enright et al. (2000a,b), Morgan \& Gill (2000), Rider et al. (2000), Hill et al. (1999), Karges et al. (1999a,b,c,d), Montgomery et al. (1999a,b; 1998), 
Vargas et al. (1999a,b), Enright et al. (1998a,b), Sparks et al. (1998), que observaram um aumento significativo do cálcio plasmático. Segundo Montegomery et al. (2000a,b), a concentração de cálcio plasmático aumentou de 150 a 170 vezes, quando do fornecimento de 5,0 ou 7,5 milhões de UI de vitamina $D_{3}$. Para Swanek (1999a,b), a concentração de cálcio plasmático aumentou de $8-48 \%$, devido principalmente ao efeito da vitamina $\mathrm{D}_{3}$ no metabolismo de cálcio, aumentando a reabsorção intestinal e a saída de cálcio de depósitos encontrados nos ossos. Ainda, em 1997, Swanek et al. observaram uma elevação do cálcio plasmático (de 9,23 mg/dL para 10,39 mg/dL) em animais suplementados com vitamina $D_{3}$.

Tabela 5. Média dos mínimos quadrados, média geral, coeficiente de correlação e significância das concentrações de minerais no plasma de animais Bos indicus suplementados com vitamina $D_{3}$ por 10 dias consecutivos antes do abate

\begin{tabular}{lccccccc}
\hline & \multicolumn{3}{c}{ Dose (x 10 UU/na/dia) } & \multicolumn{3}{c}{ Geral } \\
\multicolumn{1}{c}{ Mineral } & 0 & 3 & 6 & 9 & Média & CV & Pr>F \\
\hline Cálcio (mg/dL) & 10,56 & 11,30 & 10,79 & 11,28 & 10,99 & 6,65 & 0,11 \\
Sódio (mg/dL) & 196,10 & 203,11 & 194,31 & 203,80 & 199,30 & 5,22 & 0,13 \\
Potássio (mg/dL) & 22,18 & 24,48 & 22,54 & 22,19 & 22,79 & 20,47 & 0,71 \\
Magnésio (mg/dL) & 1,88 & 2,01 & 1,89 & 1,95 & 1,93 & 13,06 & 0,69 \\
\hline
\end{tabular}

Uma das explicações para o não aumento da concentração de cálcio plasmática é que, segundo Scanga et al. (2001), a abundância de vitamina $D_{3}$ fornecida antes do abate pode provocar nos animais uma inibição na síntese e absorção de cálcio, devido ao efeito de duas enzimas $\left(\mathrm{Ca}^{+2}-25\right.$-hidroxilase e $1 \alpha$-hidroxilase $)$ que são essenciais na formação da $1,25(\mathrm{OH})_{2}$-vtamina $\mathrm{D}_{3}$. Ou ainda que, a vitamina $\mathrm{D}_{3}$ não foi convertida nas formas metabólicas (25-hidroxivitamina $\mathrm{D}_{3}$ e $1,25(\mathrm{OH})_{2}$-vitamina $\mathrm{D}_{3}$ ), reduzindo então a absorção de cálcio, portanto, reduzindo as concentrações de cálcio sérico. Uma outra hipótese levantada por Wiegand et al. $(1998,2001)$ é sobre a forma de fornecimento de vitamina $\mathrm{D}_{3}$ para os 
animais. Existe a hipótese de que o fornecimento por cápsulas de gelatina (bolus) seja o método mais eficiente do que quando feito junto do concentrado, devido a passagem direta para o trato digestivo. Segundo Scanga et al. (2001) o fornecimento de vitamina $\mathrm{D}_{3}$ por via oral através de bolus foi efetivo, como resultado da elevação da concentração de cálcio plasmático e melhora na maciez da carne.

Para a concentração de magnésio é esperada uma redução na sua concentração, quando pelo aumento da dose de vitamina $\mathrm{D}_{3}$, o que não foi observado em nossos resultados, que mostram não haver diferença entre as doses estudadas, mas com uma pequena tendência das diferentes doses de vitamina D em aumentar a concentração de magnésio. Nossos resultados são contrários aos relatados por Swanek et al. (1997), que observaram uma redução do magnésio plasmático $(26,6 \%)$ e por Karges et al. (1999a,b,c,d), que também observaram uma redução na concentração de magnésio plasmático (com a menor concentração ocorrendo com a dose 6x106 UI/na/dia. Entretanto, segundo Hill et al. (1999), novilhos tratados com 7,5 X $10^{6}$ UI de vitamina $\mathrm{D}_{3}$ por um período de 10 dias antes do abate apresentaram pouca diferença nas concentrações de cálcio, magnésio e fósforo plasmático.

Assim podemos concluir que, a suplementação de vitamina $D_{3}$ fornecida aos animais não foi eficaz para aumentar a concentração de cálcio plasmático (provocar uma hipercalcemia) e assim demonstrar a efetividade da suplementação da vitamina $D_{3}$ em manipular a concentração de cálcio, magnésio, sódio e potássio circulante.

\subsection{Concentração de Minerais no Músculo}

Para as concentrações de cálcio, sódio, potássio e magnésio no músculo (Tabela 6) não foram encontradas diferenças $(\mathrm{P}>0,05)$ entre as doses estudadas.

Observa-se que apenas para o potássio todas as doses testadas forma superiores ao da dose controle. O mesmo efeito foi encontrado paras a concentração de magnésio muscular, que apresentou aumento linear quanto a dose de vitamina $\mathrm{D}_{3}$ oferecida. 
Tabela 6. Média dos mínimos quadrados, média geral, coeficiente de correlação e significância das concentrações de minerais no plasma de animais Bos indicus suplementados com vitamina $\mathrm{D}_{3}$ por 10 dias consecutivos antes do abate

\begin{tabular}{|c|c|c|c|c|c|c|c|}
\hline \multirow[b]{2}{*}{ Mineral } & \multicolumn{4}{|c|}{ Dose (x $\left.10^{6} \mathrm{UI} / \mathrm{na} / \mathrm{dia}\right)$} & \multicolumn{3}{|c|}{ Geral } \\
\hline & 0 & 3 & 6 & 9 & Média & $\mathrm{CV}$ & $\operatorname{Pr}>\mathrm{F}$ \\
\hline Cálcio $(\mu \mathrm{g} / \mathrm{g})$ & 122,75 & 122,75 & 121,20 & 125,40 & 123,06 & 9,58 & 0,88 \\
\hline Fósforo $(\mathrm{g} / 100 \mathrm{~g})$ & 0,66 & 0,67 & 0,67 & 0,71 & 0,68 & 7,74 & 0,21 \\
\hline Sódio $(\mathrm{g} / 100 \mathrm{~g})$ & 0,16 & 0,15 & 0,14 & 0,13 & 0,14 & 16,70 & 0,08 \\
\hline Potássio (g/100g) & 1,17 & 1,22 & 1,26 & 1,25 & 1,23 & 8,40 & 0,32 \\
\hline Magnésio $(\mu \mathrm{g} / \mathrm{g})$ & 974,13 & 986,88 & 1008,10 & 1027,30 & 1001,17 & 7,72 & 0,49 \\
\hline
\end{tabular}

Estes resultados diferem daqueles encontrados por Montegomery et al. (2002), Morgan \& Gill (2000), Rider et al. (2000), Hill et al. (1999), Swanek et al. (1999a,b,c), Montgomery et al. (1998), que encontram um aumento significativo $(\mathrm{P}<0,05)$ na concentração de cálcio muscular.

Segundo Swanek et al. (1999) a concentração de cálcio no músculo Longissimus de animais tratados com vitamina $\mathrm{D}_{3}$ aumentou de $43-50 \%$. Este aumento da concentração de cálcio poderia aumentar a capacidade das proteases cálcio-dependentes de degradar a Troponina-T em um componente de $30 \mathrm{kDa}$ no tempo de maturação de 14 dias, resultando em carne macia. Como nos resultados não houve efeito das doses de vitamina $\mathrm{D}_{3}$ sobre a concentração de cálcio muscular, espera-se que neste experimento não haja ou ocorra pouco amaciamento da carne, nos diferentes níveis de vitamina $\mathrm{D}_{3}$, devido a falta ou reduzida proteólise, através da não ativação da proteases cálcio dependentes. 


\subsection{Perdas por Evaporação (PE)}

Não houve efeito da dose de vitamina $\mathrm{D}_{3}$ e tempo de maturação sobre as PE (Tabela 7). Observa-se apenas uma pequena tendência para a dose $6 \times 10^{6} \mathrm{UI} / \mathrm{an} / \mathrm{dia}$ e o tempo de maturação de 15 dias, apresentarem os menores valores para as PE. Para o estudo do efeito "sliced" em relação a dose e o tempo de maturação não se observou diferença (NS) entre as doses de vitamina $\mathrm{D}_{3}$ nos diferentes períodos de maturação, mas um efeito significativo $(\mathrm{P}<0,01)$ para o tempo de maturação dentro da dose controle $\left(0 \times 10^{6} \mathrm{UI} / \mathrm{an} / \mathrm{dia}\right)$, que resultou no maior valor de PE.

Tabela 7. Médias dos quadrados mínimos das perdas por evaporação (\%) e efeito "sliced" em relação ao tratamento, tempo de maturação e a interação tratamento $\mathrm{X}$ tempo de maturação em carcaças de animais Bos indicus suplementados com vitamina $\mathrm{D}_{3}$ por 10 dias consecutivos antes do abate

\begin{tabular}{ccccccc}
\hline & \multicolumn{3}{c}{ Dose (x 106 UI/an/dia) } & & Ef. \\
Maturação (dias) & 0 & 3 & 6 & 9 & Média & Pr>F \\
\hline 1 & 13,13 & 11,59 & 9,40 & 13,34 & 11,86 & NS \\
8 & 16,38 & 12,53 & 12,41 & 11,48 & 13,20 & NS \\
15 & 9,91 & 8,33 & 9,20 & 11,82 & 9,81 & NS \\
Média & 13,14 & 10,81 & 10,33 & 12,21 & & \\
Ef. Sliced Pr>F & $* *$ & NS & NS & NS & & \\
\hline
\end{tabular}

Média geral= 11,59; CVgeral $=34,23 \% ;$ Pr $>$ Fgeral $=0,17$

${ }^{a} \mathrm{NS}=$ não significativo $(\mathrm{P}>0,05)$

* $\mathrm{P}(<0,05)$

$* * \mathrm{P}(<0,01)$ 


\subsection{Perdas por Gotejamento (PG)}

Para as PG (Tabela 8) houve um efeito de dose $(\mathrm{P}<0,01)$ em relação ao tempo de maturação, onde a dose $6 \times 10^{6} \mathrm{UI} / \mathrm{an} /$ dia resultou na menor PG encontrada. Para o tempo de maturação houve uma tendência da menor PG ser aquela ao dia 1 de maturação, mas observou-se que quanto maior o tempo de maturação maior a PG. Para o estudo do efeito "sliced" em relação a dose e o tempo de maturação, foi observado uma diferença significativa para a dose $0 \times 10^{6} \mathrm{UI} / \mathrm{an} / \mathrm{dia}(\mathrm{P}<0,05)$ e para a dose $9 \times 10^{6} \mathrm{UI} / \mathrm{an} / \mathrm{dia}(\mathrm{P}<0,01)$, refletidas nos resultados de maiores PG. Houve também uma diferença significativa $(\mathrm{P}<0,05)$ para o tempo de maturação de 15 dias, que também apresentou o maior valor para as PG.

Tabela 8. Médias dos quadrados mínimos de perdas por gotejamento (\%) e efeito "sliced" em relação ao tratamento, tempo de maturação e a interação tratamento $\mathrm{X}$ tempo de maturação em carcaças de animais Bos indicus suplementados com vitamina $D_{3}$ por 10 dias consecutivos antes do abate

\begin{tabular}{|c|c|c|c|c|c|c|}
\hline \multirow[b]{2}{*}{ Maturação (dias) } & \multicolumn{4}{|c|}{ Dose (x $\left.10^{6} \mathrm{UI} / \mathrm{an} / \mathrm{dia}\right)$} & & \multirow{2}{*}{$\begin{array}{c}\text { Ef. } \\
\text { Sliced } \\
\text { Pr }>\mathrm{F}\end{array}$} \\
\hline & 0 & 3 & 6 & 9 & Média & \\
\hline 1 & 9,25 & 9,99 & 8,07 & 9,33 & 9,16 & NS \\
\hline 8 & 10,99 & 10,77 & 10,16 & 11,51 & 10,86 & NS \\
\hline 15 & 11,83 & 10,73 & 9,30 & 12,02 & 10,97 & $*$ \\
\hline Média & 10,69 & 10,50 & 9,18 & 10,95 & & \\
\hline Ef. Sliced & $*$ & NS & NS & $* *$ & & \\
\hline
\end{tabular}

Média geral=10,30; $\mathrm{CV}=19,27 \% ; \mathrm{Pr}>\mathrm{F}=0,0001$

${ }^{a} \mathrm{NS}=$ não significativo $(\mathrm{P}>0,05)$

* $\mathrm{P}(<0,05)$

$* * \mathrm{P}(<0,01)$ 
Esses resultados são semelhantes aos encontrados por Karges et al. (2001), Enright et al. (1998), onde animais suplementados com vitamina $D_{3}$ apresentaram maior capacidade de retenção de água e menor porcentagem nas perdas por gotejamento, o que diretamente influenciaram em menor força de cisalhamento (FC), e maior maciez.

\subsection{Perdas totais (PT)}

Para as PT (Tabela 9) houve um efeito de dose $(\mathrm{P}<0,05)$ em relação ao tempo de maturação, onde a dose $6 \times 10^{6} \mathrm{UI} / \mathrm{an} /$ dia resultou na menor PT encontrada. Para o tempo de maturação não foi encontrada uma tendência para a menor PT, sendo que para as doses 0 e $3 \times 10^{6} \mathrm{UI} / \mathrm{an} /$ dia a menor PT ocorreu aos 15 dias maturação, e para as doses 6 e 9x10 UI/an/dia a menor PT ocorreu ao 1 dia de maturação. Para o estudo do efeito "sliced" em relação a dose e o tempo de maturação, foi observado uma diferença significativa para a dose 0 e $6 \times 10^{6} \mathrm{UI} / \mathrm{an} / \mathrm{dia}(\mathrm{P}<0,05)$, onde foram encontrados a maior e a menor PT. Houve também uma diferença significativa $(\mathrm{P}<0,05)$ para o tempo de maturação aos 1 e 15 dias, que apresentaram o maior valor para as PT.

Tabela 9. Médias dos quadrados mínimos de perdas totais (\%) e efeito "sliced" em relação ao tratamento, tempo de maturação e a interação tratamento $\mathrm{X}$ tempo de maturação em carcaças de animais Bos indicus suplementados com vitamina $\mathrm{D}_{3}$ por 10 dias consecutivos antes do abate

\begin{tabular}{|c|c|c|c|c|c|c|}
\hline \multirow[b]{2}{*}{$\begin{array}{l}\text { Maturação } \\
\text { (dias) }\end{array}$} & \multicolumn{4}{|c|}{ Dose (x $\left.10^{6} \mathrm{UI} / \mathrm{an} / \mathrm{dia}\right)$} & & \multirow{2}{*}{$\begin{array}{c}\text { Ef. } \\
\text { Sliced } \\
\text { Pr>F }\end{array}$} \\
\hline & 0 & 3 & 6 & 9 & Média & \\
\hline 1 & 22,39 & 21,57 & 17,46 & 22,67 & 21,02 & $*$ \\
\hline 8 & 27,38 & 23,29 & 22,57 & 22,99 & 24,06 & NS \\
\hline 15 & 21,74 & 19,07 & 18,50 & 23,84 & 20,78 & $*$ \\
\hline Média & 23,83 & 21,31 & 19,51 & 23,17 & & \\
\hline $\begin{array}{cc}\text { Ef. } & \text { Pr }>F \\
\text { Sliced } & \\
\end{array}$ & $*$ & NS & $*$ & NS & & \\
\hline
\end{tabular}

Média geral= 21,89; $\mathrm{CV}=18,58 \% ; \mathrm{Pr}>\mathrm{F}=0,0123$

${ }^{a} \mathrm{NS}=$ não significativo $(\mathrm{P}>0,05) ; * \mathrm{P}(<0,05) ; * * \mathrm{P}(<0,01)$ 


\subsection{Força de Cisalhamento (FC)}

Para a FC (Tabela 10) houve um efeito de dose $(\mathrm{P}<0,01)$ em relação ao tempo de maturação, onde a dose $0 \times 10^{6} \mathrm{UI} / \mathrm{an} /$ dia resultou na menor FC encontrada.

Em relação ao tempo de maturação foi encontrada uma tendência de redução, onde quanto maior o tempo de maturação, menor FC encontrada. Assim observamos um efeito positivo da maturação sobre a FC como seria esperado. Para o estudo do efeito "sliced" em relação a dose e o tempo de maturação, foi observado uma diferença significativa para todas as doses estudadas $(\mathrm{P}<0,01)$. Houve também uma diferença significativa $(\mathrm{P}<0,01)$ para $\mathrm{o}$ tempo de maturação ao 1 dia, que apresentou o maior valor para a FC.

Tabela 10. Médias dos quadrados mínimos de forca de cisalhamento $(\mathrm{Kg})$ e efeito "sliced" em relação ao tratamento, tempo de maturação e a interação tratamento $\mathrm{X}$ tempo de maturação em carcaças de animais Bos indicus suplementados com vitamina $\mathrm{D}_{3}$ por 10 dias consecutivos antes do abate

\begin{tabular}{|c|c|c|c|c|c|c|}
\hline \multirow[b]{2}{*}{ Maturação (dias) } & \multicolumn{4}{|c|}{ Dose (x $10^{6}$ UI/an/dia) } & \multirow{2}{*}{\multicolumn{2}{|c|}{$\begin{array}{c}\text { Ef. } \\
\text { Sliced } \\
\text { Pr>F }\end{array}$}} \\
\hline & 0 & 3 & 6 & 9 & & \\
\hline 1 & 4,92 & 5,56 & 4,98 & 5,69 & 5,29 & $* *$ \\
\hline 8 & 3,67 & 4,14 & 4,03 & 4,19 & 4,01 & NS \\
\hline 15 & 2,87 & 3,11 & 3,02 & 3,38 & 3,09 & NS \\
\hline Média & 3,82 & 4,27 & 4,01 & 4,42 & & \\
\hline $\begin{array}{cc}\text { Ef. } & \operatorname{Pr}>\mathrm{F} \\
\text { Sliced } & \end{array}$ & $* *$ & $* *$ & $* *$ & $* *$ & & \\
\hline $\begin{array}{l}\text { Média geral }=4,14 ; \mathrm{Cl} \\
{ }^{\mathrm{a}} \mathrm{NS}=\text { não significativ } \\
* \mathrm{P}(<0,05) \\
* * \mathrm{P}(<0,01)\end{array}$ & $\begin{array}{r}3,22 \% \\
>0,05)\end{array}$ & 0001 & & & & \\
\hline
\end{tabular}


Dessa maneira conclui-se que, nesses resultados o fornecimento de vitamina $\mathrm{D}_{3}$ não foi efetivo para promover o amaciamento da carne. Entretanto o melhor efeito no amaciamento da carne foi resultado do tempo de maturação. Esses resultados se assemelham aos encontrados por Scanga et al. (2001), Rentfrow et al. (2001), Wiegand et al. (1998, 2001), Berry et al. (2000), Ribeiro (2000), Hill et al. (1999), SPARKS et al. (1998) que não observaram uma redução na força de cisalhamento, mesmo que a suplementação com vitamina $\mathrm{D}_{3}$ elevasse a concentração de cálcio plasmático. Resultados apresentados por Karges et al. (2001), Kotrla et al. (2001), Foote et al. (2001), Montgomery et al. (2001a,b; 2000a,b; 1988), Boleman et al. (2000), Morgan \& Gill (2000), Rider et al. (2000), Karges et al. (1999a,b,c,d), Meredith \& Morgan (1999), MORGAN et al. (1999), Vargas et al. (1999a,b), Swanek (1999a,b,c), Beitz et al. (1997) e Swanek et al. (1997), que encontraram amaciamento da carne, pelo uso da suplementação com vitamina $\mathrm{D}_{3}$, entre 6,6-50\%, diferem dos encontrados.

Segundo Montegomery et al. (2002) e Karges et al. (1999a), a suplementação com vitamina $\mathrm{D}_{3}$ deve ser efetiva no amaciamento da carne, quando a carne dos animais forem duras e com pouco ou nenhum impacto sobre a carne de animais que tenham carne macia. Em nossos resultados observamos que mesmo em animais de carne supostamente menos macia, a suplementação não resultou em amaciamento da carne, diferindo assim do resultado encontrado pelos referidos pesquisadores.

\subsection{Análise Sensorial}

Para as características estudadas na análise sensorial (Tabela 11), somente a suculência não apresentou diferença significativa $(P>0,05)$, quanto a dose de vitamina $\mathrm{B}$ utilizada.

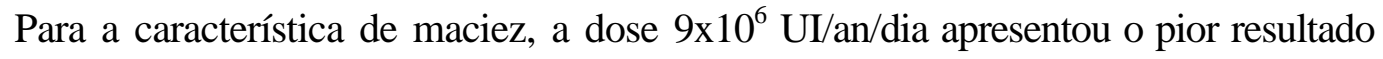
(carne com maior maciez sensorial, menos macia) e, o melhor resultado foi aquele resultante 
da dose $3 \times 10^{6} \mathrm{UI} / \mathrm{an} /$ dia. Para sabor o melhor resultado foi aquele conseguido com a dose $3 \times 10^{6} \mathrm{UI} / \mathrm{an} /$ dia e o pior para as demais doses de vitamina $\mathrm{D}_{3}$. Numa avaliação geral, a pior avaliação foi para a dose $0 \times 10^{6} \mathrm{UI} / \mathrm{an} /$ dia e a melhor avaliação para a dose $3 \times 10^{6} \mathrm{UI} / \mathrm{an} / \mathrm{dia}$.

Tabela 11. Valores médios das características de sabor, suculência, maciez e análise geral da análise sensorial realizada em carcaças de animais Bos indicus suplementados com vitamina $\mathrm{D}_{3}$ por 10 dias consecutivos antes do abate

\begin{tabular}{|c|c|c|c|c|c|c|}
\hline \multirow[b]{2}{*}{ Característica $^{1}$} & \multicolumn{4}{|c|}{ Dose (X $\left.10^{6} \mathrm{UI} / \mathrm{an} / \mathrm{dia}\right)$} & \multirow[b]{2}{*}{$\begin{array}{c}\text { Média } \\
\text { geral }\end{array}$} & \multirow[b]{2}{*}{$\mathrm{CV}(\%)$} \\
\hline & 0 & 3 & 6 & 9 & & \\
\hline Maciez & $5,38^{\mathrm{ab}}$ & $4,88^{b}$ & $5,10^{\mathrm{ab}}$ & $5,86^{\mathrm{a}}$ & 5,31 & 29,18 \\
\hline Sabor & $5,44^{\mathrm{a}}$ & $4,32^{b}$ & $5,40^{\mathrm{a}}$ & $5,18^{\mathrm{a}}$ & 5,09 & 27,90 \\
\hline Suculência & $4,72^{\mathrm{a}}$ & $4,14^{\mathrm{a}}$ & $4,76^{\mathrm{a}}$ & $4,96^{\mathrm{a}}$ & 4,65 & 34,42 \\
\hline Geral & $5,44^{\mathrm{a}}$ & $4,56^{\mathrm{b}}$ & $5,32^{\mathrm{a}}$ & $5,26^{\mathrm{ab}}$ & 5,15 & 26,53 \\
\hline
\end{tabular}

Assim, pode-se concluir que, na análise sensorial os melhores resultados foram aqueles obtidos com a dose $3 \times 10^{6} \mathrm{UI} / \mathrm{an} /$ dia. De uma maneira geral a suplementação com vitamina $\mathrm{D}_{3}$ melhora as características sensoriais da carne. Esses resultados se assemelham aos encontrados por Swanek (1999 a,b), que mostraram um efeito positivo da suplementação com vitamina $\mathrm{D}_{3}$ sobre as características sensoriais da carne. Outros pesquisadores como Karges et al. (2001), Montegomery et al. (2000a,b) e Rider et al. (2000) não detectaram o efeito da suplementação na análise sensorial. 


\section{CONCLUSÕES}

Para o presente trabalho podemos concluir que:

- Não foram encontradas diferenças significativas para as principais características da carcaça. As características de espessura da gordura (EG), espessura de gordura/100 kg carcaça resfriada (EG/100), temperatura à 0 hs $(\mathrm{T} 0)$, porcentagem do dianteiro (PD) e porcentagem de ponta de agulha (PPA) foram significativas a 5\%;

- A glicose plasmática não apresentou diferença significativa $(\mathrm{P}>0,05)$ entre as doses de vitamina $\mathrm{D}_{3}$ estudadas;

- Para as concentrações de cálcio, sódio, potássio e magnésio no plasma não foram encontradas diferenças $(\mathrm{P}>0,05)$ entre as doses estudadas;

- Para as concentrações de cálcio, sódio, potássio e magnésio no músculo não foram encontradas diferenças $(\mathrm{P}>0,05)$ entre as doses estudadas;

- Não houve efeito da e tempo de maturação sobre as PE, apenas uma pequena tendência para a dose $6 \times 10^{6} \mathrm{UI} / \mathrm{an} /$ dia e o tempo de maturação de 15 dias, apresentarem os menores valores para as PE;

- Para as PG houve um efeito de dose $(\mathrm{P}<0,01)$ em relação ao tempo de maturação, onde a dose $6 \times 10^{6} \mathrm{UI} / \mathrm{an} /$ dia resultou na menor PG encontrada, havendo também uma diferença significativa $(\mathrm{P}<0,05)$ para o tempo de maturação de 15 dias, que também apresentou o maior valor para as PG;

- Para as PT houve um efeito de dose $(\mathrm{P}<0,05)$ em relação ao tempo de maturação, onde a dose $6 \times 10^{6} \mathrm{UI} / \mathrm{an} /$ dia resultou na menor PT encontrada. Para o tempo de maturação não foi encontrada uma tendência para a menor PT, sendo que para as doses 0 e $3 \times 10^{6}$ 
UI/an/dia a menor PT ocorreu aos 15 dias maturação, e para as doses 6 e 9x10 UI/an/dia ao dia 1 de maturação;

- Para a FC houve um efeito de dose $(\mathrm{P}<0,01)$ em relação ao tempo de maturação, onde $0 \times 10^{6} \mathrm{UI} / \mathrm{an} /$ dia resultou na menor FC encontrada. Em relação ao tempo de maturação foi encontrada uma tendência de redução, onde quanto maior o tempo de maturação, menor a FC;

- Para as características estudadas na análise sensorial, a dose $3 \times 10^{6} \mathrm{UI} / \mathrm{an} / \mathrm{dia}$ afetou positivamente as características maciez, sabor e avaliação geral. Para a suculência não foi encontrada diferença significativa $(\mathrm{P}>0,05)$, quanto às doses utilizadas. 


\section{REFERÊNCIAS BIBLIOGRÁFICAS}

AMERICAN MEAT SCIENCE ASSOCIATION. Guidelines for cookery and sensory evaluation of meat. Illinois: National Livestock and Meat Board, 1978. 24p.

ANDRIGUETTO, J.M.; MINARDI, I.; PERLY, L.; GEMAEL, A.; FLEMMING, J.S.; SOUZA, G.A.; BONA FILHO, A. Nutrição animal. 4.ed. São Paulo:Nobel, 1981. 1v.

BEITZ, D. TRENKLE, A; PARRISH, F.; MONTEGOMERY, J.; HORST, R. Feeding of vitamin $D_{3}$ is a potential method to improve tenderness of beef. 1997 Dairy Report, Iowa State University, DSL 145, 4p., 1997.

http://www.extension.iastate.edu/Pages/dairy/report97/products/dsl-145.pdf (21 jan. 2002)

BERRY, B.A.; GILL, D.R.; BALL, R. Effects of feeding vitamin D on feedlot performance, carcass traits, and meat tenderness of finishing steers. 2000 Animal Science Research Report, Oklahoma State University, p.98-103, 2000.

http://www.ansi.okstate.edu/research/2000rr/19.htm (22 jan. 2002)

BLEZINGER, S.B. Small vitamin imbalances can be critical. Walden Farms - Cattle Today online, June 2001. http://cattletoday.com/archive/2001/june/CT153shtml (20 dez. 2001)

BOLEMAN, C.T.; RAMSEY, W.S.; PELL, R.K.; SAVELL, J.W. Mechanisms of vitamin $\mathrm{D}_{3}$ on tenderness of lamb. Sheep and Goat, Wool and Mohair Combined Research Reports, p.10-18, September 2000.

http://sanangelo.tamu.edu/genetics/shgrep00.htm. (20 dez. 2001) 
BONDI, A.A. Nutricion animal. Zaragoza:Acribia, 1988. p.244-250.

DIKEMAN, M.E.; GREEN, R.D.; WULF, D.M. Effects of genetics vs management on beef tenderness. Vitamin D supplementation. Beef Improvement Federation, 6p., 2000. http://www.beefimprovement.org/BIFfact_tenderness.html. (20 dez. 2001)

ENRIGHT, K.L.; ANDERSON, B.K.; ELLIS, M.; McKEITH, F.K.; BERGER, L.L.; BAKER, D.H. The effects of feeding high levels of vitamin $\mathrm{D}_{3}$ on pork quality. Journal of Animal Science, v.76, suppl. 1, p.149, 1998.

ENRIGHT, K.L.; MILLER, K.D.; BERGER, L.L.; McKEITH, F.K.; LYNCH, G.; ELLIS, M. Influence of level of vitamin $\mathrm{E}$ and level and time of feeding of vitamin $\mathrm{D}_{3}$ on growth, carcass, and pork quality characteristics in pigs. Journal of Animal Science, v.78, suppl. 2, p.49-50, 2000.

ENRIGHT, K.L.; ELLIS, M.; McKEITH, F.K.; BERGER, L.L.; BAKER, D.H.; ANDERSON, B.K. The influence of level of dietary vitamin $\mathrm{D}_{3}$. Pork Quality. Porknet-Pork on The Information Superhighway, 10p., 2000.

http://poknet.outreach.uiuc.edu/fulltext.cfm?section=2\&documentID=110 $(20 \mathrm{dez} .2001)$

FELÍCIO, P.E. A carcaça Nelore para o desossador. In: SEMINÁRIO MANAH “ O NELORE PARA CARNE”, 5., Brotas, 1995. Anais. Brotas: Fazenda Mundo Novo, 1995. p.18-34.

FNP CONSULTORIA \& COMÉRCIO. ANUALPEC 2001: anuário da pecuária brasileira. São Paulo, 2001. 359p.

FOOTE, M.R.; BEITZ, D.C.; HORST, R.L.; HUFF-LONERGAN, E.J.; TRENKLE, A.H.; PARRISH JR., F.C. Use of vitamin $\mathrm{D}_{3}$ and its metabolites to improve beef tenderness. 2001 Beef Research Report, Iowa State University, A.S. Leaflet R 1765, p.133-137, 20001. 
http://www.extension.iastate.edu/Pages/ansci/beefreports/asl1765.pdf (21 jan. 2002)

GAMAN, P.M.; SHERRINGTON, K.B. Science of food: an introduction to food science, nutrition and microbiology. 2.ed. Oxford:Pergamon Press, 1981. p. 01-103.

HILL, G.M.; BRITO, G.; PRINGLE, T.D.; WILLIAMS, S.E. Performance, plasma Ca, P and $\mathrm{Mg}$, carcass characteristics, and meat tenderness in beef steers fed high levels of vitamin D3. Journal of Animal Science, v.77, suppl. 1, p.18-19, 1999.

KARGES, K.; MORGAN, J.B.; OWENS, F.N.; GLL, D.R. Effects of feeding vitamin D on feed intake, carcass characteristics, and meat tenderness of beef steers. 1999 Animal Science Research Report, Oklahoma State University, p.134-142, 1999a.

http://www.ansi.okstate.edu/research/1999rr/23.htm (22 jan. 2002)

KARGES, K.; OWENS, F.N.; GILL, D.R.; MORGAN, J.B. Effects of supplemental vitamin D levels on feed intake and blood minerals of yearling steers. 1999 Animal Science Research Report, Oklahoma State University, p.134-142, $1999 \mathrm{~b}$.

http://www.ansi.okstate.edu/research/1999rr/24.htm (22 jan. 2002)

KARGES, K.; MORGAN, J.B.; OWENS, F.N.; GILL, D.R. Effects of supplemental vitamin D on blood parameters, calpastatin activity and pH of steer carcasses. 1999 Animal Science Research Report, Oklahoma State University, p.143-146, 1999c.

http://www.ansi.okstate.edu/research/1999rr/25.htm (22 jan. 2002)

KARGES, K.; MORGAN, J.B.; OWENS, F.N.; GILL, D.R. Effects of feeding vitamin D3 on carcass characteristics of beef cattle. Journal of Animal Science, v.77, suppl. 1, p.172173, 1999d.

KARGES, K.; BROOKS, J.C.; GILL, D.R.; BREAZILE, J.E.; OWENS, F.N.; MORGAN, J.B. Effects of supplemental vitamin D3 on feed intake, carcass characteristics, tenderness, and 
muscle properties of beef steers. Journal of Animal Science, v.79, n.11, p.2844-2850, 2001.

KOTRLA, L.A.; STANKO, R.L.; TIPTON, N.C.; PASCHAL, J.C. Effect of vitamin $D_{3}$ supplementation on carcass tenderness in Brahman-based cattle. Journal of Animal Scie nce, v.79, suppl. 2, p.9-10, 2001.

MAYNARD, L.A.; LOOSLI, J.K.; HINTZ, H.F.; WARNER, R.G. Animal nutrition, 7.ed. New York:McGraw-Hill, 1979. 602 p.

MERCK. Calcium Metabolism. The Merck Manual, Section, 2, Chapter 12, 12p., 2001. http://www.merck.com/pubs/mmanual/section2/chapter12/12.htm (20 dez. 2001)

MEREDITH, G.; MORGAN, B. Effects of vitamin $D_{3}$ on beef carcass characteristics. 1999 Research Highlights, Oklahoma Panhandle Research \& Extension Center, p.40, 1999. http://www.org.okstate.edu/goodwell/Publications/Reseach\%20Highlights\%20PDF.pdf dez. 2001)

MONTGOMERY, J.L.; PARRISH, JR., F.C.; BEITZ, D.C.; HORST, R.L.; HUFFLONERGAN, E.J.; TRENKLE, A.H. Feeding supplemental dietary vitamin $\mathrm{D}_{3}$ to improve beef tenderness. 1998 Beef Research Report, Iowa State University, A.S. Leaflet R 1549, p.3, 1998.

http://www.extension.iastate.edu/Pages/ansci/beefreports/meats98.html (21 jan. 2002)

MONTGOMERY, J.L.; CARR, M.A.; KERTH, C.R.; HILTON, G.G.; BEHRENDS, L.L.; BEHRENDS, E.R.; MILLER, M.F. Dietary modifications using vitamin $\mathrm{D}_{3}$ to improve beef tenderness. Journal of Animal Science, v.77, suppl. 1, p.45, 1999a.

MONTGOMERY, J.L.; HORST, R.L.; HOY, D.A.; CARR, M.A.; HILTON, G.G.; PRICE, B.D.; MILLER, M.F. Effects of dietary modifications using vitamin D3 on calcium content 
and vitamin D residues in tissue and liver. Journal of Animal Science, v.77, suppl. 1, p.173, 1999b.

MONTGOMERY, J.L.; PARRISH, JR., F.C.; BEITZ, D.C.; HORST, R.L.; HUFFLONERGAN, E.J.; TRENKLE, A.H. The use of vitamin $\mathrm{D}_{3}$ to improve beef tenderness. Journal of Animal Science, v.78, n.10, p.2615-2621, 2000a.

MONTGOMERY, J.L.; GENTRY, J.G., BEHRENDS, L.L.; BEHRENDS, E.R.;HILTON, G.G.; GALYEAN, M.; BLANTON, J.R.; BARHAM, A.; BARHAM, B.; MILLER, M.F. Supplemental vitamin $D_{3}$ improves beef tenderness. Journal of Animal Science, v.78, suppl. 1, p.159, 2000b.

MONTGOMERY, J.L.; MORROW JR., MILLER, M.F. Characterization of muscle degradation from vitamin $\mathrm{D}_{3}$ supplementation of feedlot steers using a muscle cell culture system. Journal of Animal Science, v.78, suppl. 1, p.159, 2000c.

MONTGOMERY, J.L.; MORROW JR., K.J.; HORST, R.L.; BLANTON JR., J.R.; MILLER, M.F. Subcellular differences in muscle calcium and phosphorus due to vitamin D3 supplementation of beef cattle. Journal of Animal Science, v.79, suppl. 2, p.1, 2001a.

MONTGOMERY, J.L.; MILLER, M.F.; BLANTON JR., J.R.; HORST, R.L. Using vitamin $\mathrm{D}_{3}$ to improve beef tenderness in three different breed types. Final Report, Texas Tech University, 25p., $2001 b$. http://www.asft.ttu.edu/cfire/reports/CFIRE\%20report\%20vitD.pdf (22 jan. 2002)

MONTGOMERY, J.L.; CARR, M.A.; KERTH, C.R.; HILTON, G.G.; PRICE, B.P.; GALYEAN, M.L.; HORST, R.L.; MILLER, M.F. Effect of vitamin $D_{3}$ supplementation level on the postmortem tenderization of beef from steers. Journal of Animal Science, v.80, n.4, p.971-981, 2002. 
MORGAN, J.B. Pre-harvest nutritional management. Cattlemen's College, Consumer Demand Strategies, Denver, Colorado, 4p., July 17, 1998a.

http://www.beef.org (20 dez. 2001)

MORGAN, J.B. Vitamins $D_{3}$ and E. 1998 Feed Composition Guide, 2p., 1998b. http://content.com/feedcomp/feed983.htm (22 jan. 2002)

MORGAN, J.B.; DOLEZALL, H.G.; GILL, D.R. Vitamin D supplementation improves beef tenderness. Nebraska Veterinary and Biomedical Sciences Newsletter, v.28, n.10, p.4, October 1999.

http://nvdls.unl.edu/newslet99/oct99.htm (20 dez. 2001)

MORGAN, J.B.; GILL, D.R. Influencing beef tenderness through manipulation of calcium metabolism with vitamin D. Journal of Animal Science, v.78, suppl. 1, 23p.,2000.

NAKAMURA, R. Factors associated with postmortem increase of extractable $\mathrm{Ca}$ in chicken breast muscle. Journal of Food Science, v.38, n.7, p.1113-1114, 1973.

NATIONAL RESEARCH COUNCIL. Nutrient Requirements of Beef Cattle. 7.ed. Washington, D.C.: National Academy Press, 1996. 76-77p.

NIHCC. Facts about dietary supplements: Vitamin D. NIH Clinical Center, National Institutes of Health, 10p., 2001.

http://www.cc.nih.gov/cc/supplements/vitd.html (20 dez. 2001)

RENTFROW, G.K.; BERGER, L.; CARR, T.; MeKEITH, F.; BREWER, M.S.; BERG, E.P. The effects of feeding elevated levels of vitamins $D_{3}$ and $E$ on beef longissimus tenderness. Journal of Animal Science, v.79, suppl. 2, p.56, 2001. 
RIBEIRO, F.G. Características de carcaça e qualidade da carne de tourinhos alimentados com dietas de alta energia. Pirassununga, 2000. 70p. Dissertação (Mestrado) - Faculdade de Zootecnia e Engenharia de Alimentos, Universidade de São Paulo.

RIDER, N.C.; MIKEL, W.B.; BEHRENDS, J.M.; SCALETTI, R.W.; XIONG, Y.L.; AARON, D.K. Effects of dietary vitamin $\mathrm{D}_{3}$ supplementation of cull beef cows on longissimus and semitendinosus muscle tenderness. Journal of Animal Science, v.78, suppl. 2, p.16, 2000.

ROCHE. Vitamin D. Roche Vitamins: vitamin D in animal nutrition, 8p., 2000. http://www.roche.com/vitamins/what/anh/vits/vitd.html (20 dez. 2001)

SAS statistical system user's guide: Stat, Version 6, 4.ed., Cary: SAS Institute, 1990. v.2.

SCANGA, J.A.; BELK, K.E.; TATUM, J.D.; SMITH, G.C. Supranutritional oral supplementation with vitamin $\mathrm{D}_{3}$ and calcium and the effects on beef tenderness. Journal of Animal Science, v.79, n.4, p.912-918, 2001.

SPARKS, J.C.; WIEGAND, B.R.; PARRISH JR., F.C.; EWAN, R.C.; HORST, R.L.; TRENKLE, A.H.; BEITZ, D.C. Effects of short term feeding of vitamin $\mathrm{D}_{3}$ on pork quality. 1998 Beef Research Report, Iowa State University, A.S. Leaflet R1613,p.3, 1998. http://www.extension.iastate.edu/Pages/ansci/swinereports/asl-1613pdf (21 jan. 2002)

STATON, T.L. Vitamins for finishing Cattle. 1998 Feed Composition Guide, 3p., 1998. http://content.com/feedcomp/feed992.htm (22 jan. 2002)

SWANEK, S.S.; MORGAN, J.B.; OWENS, F.N.; DOLEZAL, H.G.; GILL, D.R. Effects of supplemental vitamin $D_{3}$ on meat tenderness. 1997 Animal Science Research Report, Oklahoma State University, p.73-78, 1997. http://www.ansi.okstate.edu/research/1997rr/014.htm (22 jan. 2002) 
SWANEK, S.S.; ELAM, N.A.; MORGAN, J.B.; OWENS, F.N.; GILL, D.R.; STRASIA, C.A.; DOLEZAL, H.G.; RAY, F.K. Supplemental vitamin $\mathrm{D}_{3}$ and beef tenderness. 1999 Animal Science Research Report, Oklahoma State University, p.59-66, 1999a. http://www.ansi.okstate.edu/research/1999rr/10.htm (22 jan. 2002)

SWANEK, S.S.; MORGAN, J.B.; OWENS, F.N.; GILL, D.R.; STRASIA, C.A.; DOLEZAL, H.G.; RAY, F.K. Vitamin $\mathrm{D}_{3}$ supplementation of beef steers increases longissimus tenderness. Journal of Animal Science, v.77, n.4, p.874-881, 1999b.

SWANEK, S.S.; ELAM, N.A.; MORGAN, J.B.; OWENS, F.N.; GILL, D.R.; STRASIA, C.A.; DOLEZAL, H.G.; RAY, F.K. Supplemental vitamin D3 and beef tenderness. Journal of Animal Science, v.77, suppl. 1, p.172, 1999c.

TAYLOR, M.A.J.; ETHERINGTON, D.J. The solubilization of myofibrillar proteins by calcium ions. Meat Science, v.29, n.3, p.211-219, 1991.

VARGAS, D.N.; DOWN, A.E.; WEBB, D.S.; HAN, H.; MORGAN, J.B.; DOLEZAL, H.G. Effects of dietary supplementation of feedlot steers with vitamins $E$ and $\mathrm{D}_{3}$ on live performance, carcass traits, shelf-life attributes and longissimus muscle tenderness. 1999 Animal Science Research Report, Oklahoma State University, p.59-66, 1999a. http://www.ansi.okstate.edu/research/1999rr/11.htm (22 jan. 2002)

VARGAS, D.N.; DOWN, A.E.; WEBB, D.S.; HAN, H.; MORGAN, J.B.; DOLEZAL, H.G. Effect of supplementing feedlot steers with vitamin D3 and E on carcass traits, shelf-life attributes and longissimus muscle tenderness. Journal of Animal Science, v.77, suppl. 1, p.172, $1999 b$.

WEISS, W.P. Requirements of fat-soluble vitamins for dairy cows: a review. Journal of Dairy Science, v.81, n.9, p.2493-2501, 1998. 
WHIPPLE, G.; KOOHMARAIE, M.; DIKEMAN, M.E.; CROUSE, J.D.; HUNT, M.C.; KLEMM, R.D. Evaluation of attributes that affect longissimus muscle tenderness in Bos taurus and Bos indicus cattle. Journal of Animal Science, v. 68, n.9, p.2716-2728, 1990.

WIEGAND, B.R.; THIEL, R.L.; PARRISH JR., F.C.; MORRICAL, D.G. Feeding high levels of vitamin $\mathrm{D}_{3}$ to improve tenderness of callipyge lamb muscles. Journal of Animal Science, v.76, suppl. 1, p.48, 1998.

WIEGAND, B.R.; PARRISH JR., F.C.; MORRICAL, D.G.; HUFF-LONERGAN, E. Feeding high levels of vitamin $\mathrm{D}_{3}$ does not improve tenderness of callipyge lamb loin chops. Journal of Animal Science, v.79, n.8, p.2086-2091, 2001. 